\title{
Prevalence and Clinical Features of Sessile Serrated Polyps: A Systematic Review
}

\author{
Reinier G. S. Meester, ${ }^{1,2}$ Marinika M. A. G. C. van Herk, ${ }^{2}$ Iris Lansdorp-Vogelaar, ${ }^{2}$ and \\ Uri Ladabaum ${ }^{1}$
}

${ }^{1}$ Department of Medicine, Stanford University, Stanford, California; and ${ }^{2}$ Department of Public Health, Erasmus Medical Center University Medical Center, Rotterdam, The Netherlands

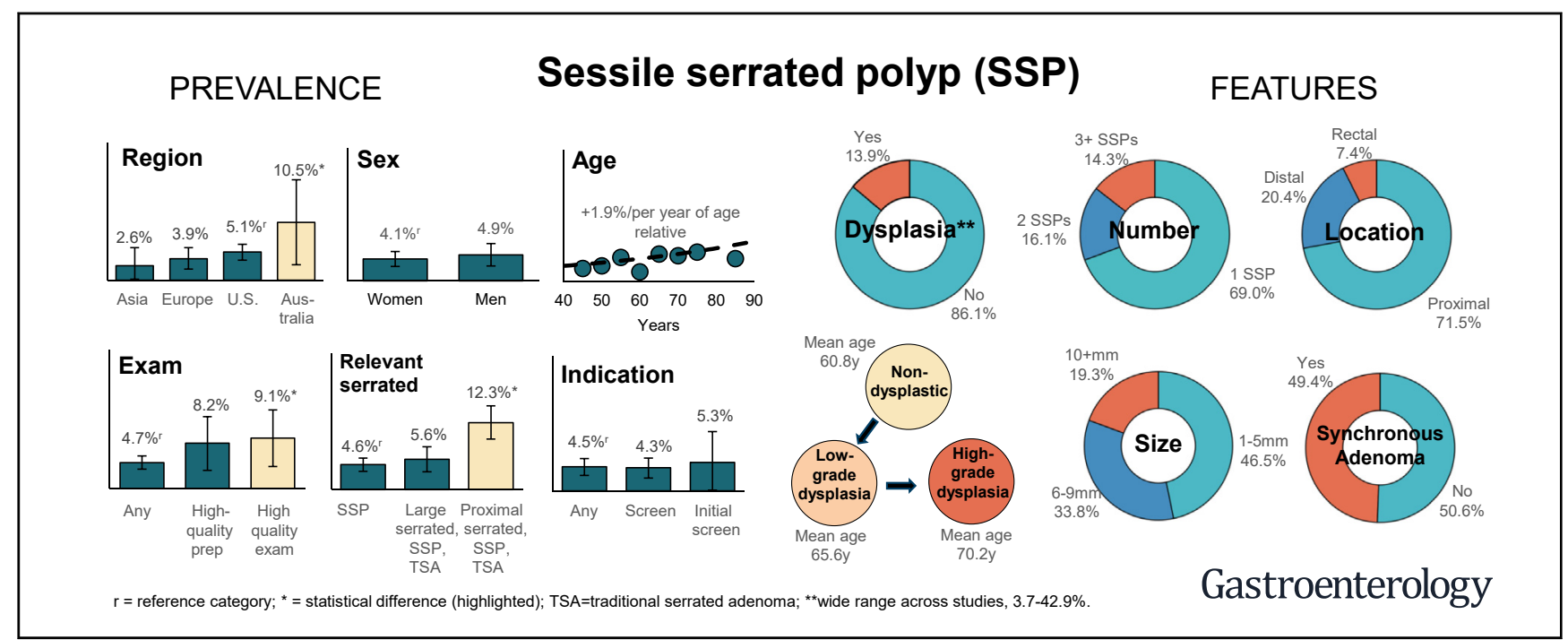

BACKGROUND \& AIMS: Sessile serrated polyps (SSPs) could account for a substantial proportion of colorectal cancers. We aimed to increase clarity on SSP prevalence and clinical features. METHODS: We performed a systematic review of MEDLINE, Web of Science, Embase, and Cochrane databases for original studies published in English since 2000. We included studies of different populations (United States general or similar), interventions (colonoscopy, autopsy), comparisons (world regions, alternative polyp definitions, adenoma), outcomes (prevalence, clinical features), and study designs (crosssectional). Random-effects regression was used for metaanalysis where possible. RESULTS: We identified 74 relevant colonoscopy studies. SSP prevalence varied by world region, from $2.6 \%$ in Asia (95\% confidence interval [CI], 0-5.9) to $10.5 \%$ in Australia (95\% CI, 2.8-18.2). Prevalence values did not differ significantly between the United States and Europe $(P=.51)$; the pooled prevalence was $4.6 \%(95 \% \mathrm{CI}, 3.4-5.8)$, and SSPs accounted for $9.4 \%$ of polyps with malignant potential $(95 \% \mathrm{CI}$, 6.6-12.3). The mean prevalence was higher when assessed through high-performance examinations (9.1\%; 95\% CI, 4.0$14.2 ; P=.04)$ and with an alternative definition of clinically relevant serrated polyps $(12.3 \%$; $95 \% \mathrm{CI}, 9.3-15.4 ; P<.001)$. Increases in prevalence with age were not statistically significant, and prevalence did not differ significantly by sex. Compared with adenomas, a higher proportion of SSPs were solitary (69.0\%; 95\% CI, 45.9-92.1; $P=.08)$, with diameters of $10 \mathrm{~mm}$ or more $(19.3 \%$; 95\% CI, 12.4-26.2; $P=.13$ ) and were proximal (71.5\%; 95\% CI,
63.5-79.5; $P=.008$ ). The mean ages for detection of SSP without dysplasia, with any or low-grade dysplasia, and with high-grade dysplasia were 60.8 years, 65.6 years, and 70.2 years, respectively. The range for proportions of SSPs with dysplasia was $3.7 \%-42.9 \%$ across studies, possibly reflecting different study populations. CONCLUSIONS: In a systematic review, we found that SSPs are relatively uncommon compared with adenoma. More research is needed on appropriate diagnostic criteria, variations in detection, and long-term risk.

Keywords: Colon Cancer; Neoplasm; PICOS; US.

Colorectal cancer (CRC) is a leading cause of cancer deaths. ${ }^{1}$ The disease develops primarily from precancerous lesions called adenomas. ${ }^{2}$ In a series of seminal papers from the 1970s and 1980s, ${ }^{3,4}$ this process was first characterized as relatively slow, with many adenomas

Abbreviations used in this paper: $\mathrm{Cl}$, confidence interval; $\mathrm{CRC}$, colorectal cancer; SSP, sessile serrated polyp; WHO, World Health Organization.

Most current article

(C) 2020 by the AGA Institute $0016-5085 / \$ 36.00$

https://doi.org/10.1053/j.gastro.2020.03.025 


\section{WHAT YOU NEED TO KNOW \\ BACKGROUND \& CONTEXT}

Sessile serrated polyps (SSPs) might account for $30 \%$ of colorectal cancers, but there is uncertainty about SSP prevalence and clinical features.

\section{NEW FINDINGS}

In a systematic review, we found the reported prevalence of SSPs to be less than $5 \%$, on average, with limited variation by age and sex. However, prevalence varies with study location, diagnostic criteria, and examination quality. SSPs are solitary, large, and proximal relatively often; the proportion that have dysplasia, based on cytologic analysis, varied widely across studies, possibly reflecting population differences.

\section{LIMITATIONS}

Cancer risk could not be assessed.

IMPACT

Standardized diagnostic criteria, training, and quality verification for endoscopists and pathologists should be considered to ensure adequate SSP detection, diagnosis and removal. Additional research is needed to determine differences in prevalence with age and among different locations, and long-term risk.

resulting in relatively few cancers. Because adenomas are detectable and removable at endoscopy, CRC is highly amenable to screening, as was first shown in the National Polyp Study in 1993.

More recently, it has been suggested that CRC may also arise from an alternative pathway with serrated polyp precursors., $^{6,7}$ Because serrated polyps were generally considered innocuous until the World Health Organization (WHO) included them in its manual for tumor classification of the digestive system, ${ }^{8}$ relatively little is known about their epidemiology and risk. ${ }^{9}$ The serrated polyp family includes sessile serrated polyps (SSPs), also known as sessile serrated adenomas or lesions; traditional serrated adenomas, and hyperplastic polyps. Hyperplastic polyps are the most common, and, especially, small distal hyperplastic polyps are not believed to harbor risk of malignancy. Traditional serrated adenomas are the most rare and can lead to CRC. SSPs appear to be substantially less common than adenomas, ${ }^{10}$ but their associated molecular features may be overrepresented among CRC cases, ${ }^{11,12}$ suggesting potentially higher risk of CRC compared to adenomas.

In this study, we sought to increase clarity on the prevalence and clinical features of SSPs by systematically reviewing the relevant literature from the last 2 decades. Review outcomes included prevalence by age, sex, and clinical definition; the multiplicity, size, and localization; and the proportion with cytologic dysplasia, the pathologic bridge to cancer.

\section{Methods}

\section{General Study Design}

The review was planned and designed in consultation with Stanford and Erasmus University librarians and consisted of 6 steps: (1) defining the scope, (2) literature search, (3) literature review and selection, (4) quality appraisal, (5) data abstraction, and (6) statistical analysis. Two different investigators performed steps 3-5 independently, with disagreements resolved through consensus.

\section{Scope of the Review}

We addressed several research questions under 5 main headers (Supplementary Table 1): the (1) prevalence and (2) clinical features of SSPs. Specific research questions under the first header included the prevalence by (1a) calendar year; (1b) world region; (1c) clinical definition; (1d) age/sex; (1e) indication for the prevalence assessment (eg, CRC screening vs follow-up of occult blood in stool); and (1f) quality of the examination (with high quality defined as examination with enhanced endoscopes or by providers from the upper quartile [minimum] of SSP detection rate). In addition, (1g) the fraction of SSPs among all potentially precancerous polyps (including adenomas, SSPs, or traditional serrated adenomas) was also assessed to gain insight into the relative proportions of polyps vs CRCs with characteristics of the serrated pathway. ${ }^{13}$ Specific research questions under the second header included (2a) polyp number, (2b) size, (2c) anatomic location, (2d) coexistence with adenoma, and (2e) presence and (2f) age at detection of cytologic dysplasia.

Most research questions focused entirely on SSPs according to strict histopathologic criteria. $^{8}$ Because what is considered a clinically relevant serrated polyp and pathologists' attention to the difference between sessile serrated and hyperplastic polyps have all evolved over time, under research question 1c, we also considered various more liberal definitions for clinically relevant serrated polyps as encountered in the literature, including large and/or proximal hyperplastic polyps in addition to the more strict histologic definition. Under research question 1c only, we also considered inclusion of traditional serrated adenomas. Reported definitions were grouped into 3 different categories: (1) older terminology used before the 2010 WHO classification of tumors, ${ }^{8}$ consisting of large hyperplastic polyps ( $\geq 10 \mathrm{~mm}$ in diameter), proximal hyperplastic polyps (located proximal of the splenic flexure), and serrated adenomas (including but not distinguishing SSPs and traditional serrated adenoma); (2) strict terminology similar to the histopathologic criteria from the 2010 WHO classification manual, consisting of only SSPs and traditional serrated adenomas; and (3) more recently introduced composite definitions, including clinically relevant histology, size, and location. The latter category combined SSP and traditional serrated adenomas, with either any large hyperplastic polyps (with large distal polyps excluded for some studies) or any proximal hyperplastic polyps (with large distal polyps included for some studies).

\section{Literature Search}

Ovid MEDLINE, Web of Science, Embase, and the Cochrane database were searched from January 1, 2000, through April 19, 2018, for original studies on serrated polyps written in English. General search terms were used to minimize the risk of missed information (Supplementary Table 2). 


\section{Literature Review and Selection}

Covidence systematic review software was used to manage references, discard duplicates, review literature, and compare reviewer decisions. Selection of studies by each reviewer was based on scanning titles and abstracts, followed by potential full-text review. Studies were selected according to predefined criteria for Population, Intervention, Comparison, Outcome, and Study Design (PICOS) (Supplementary Table 1). The target population was the US general population, with data from other world regions included for research question $1 \mathrm{a}$ and $1 \mathrm{~b}$ and for other research questions if not statistically significantly different from the United States under $1 \mathrm{~b}$. The intervention was colonoscopy or autopsy with pathologic assessment of findings. The comparators depended on the research question and included prevalence data from other world regions and CRC incidence data ${ }^{14}$ for research question $1 b$, alternative definitions for clinically relevant serrated lesions for research question 1c, and adenoma data from 11 autopsy studies (identified elsewhere ${ }^{15}$ and not systematically reviewed here $)^{16-26}$ for research questions $1 \mathrm{~d}$ and $2 \mathrm{a}-\mathrm{c}$. The outcome of interest was the percentage of the population with SSPs or the percentage of SSPs with the feature of interest, relying on study criteria for the diagnosis of SSPs. The study design was cross sectional.

\section{Quality Appraisal}

There is no standard instrument for quality appraisal of prevalence studies. Therefore, we modified a validated tool designed for the appraisal of studies measuring the prevalence of lower back pain, ${ }^{27}$ answering only the 8 of the 10 questions deemed pertinent to our study design (Supplementary Table 3). Assessment criteria concerned study characteristics such as the method of sampling, the case definition, and the study instrument. The overall risk of bias was qualified as low, moderate, or high depending on the level of confidence in the study estimates.

\section{Data Abstraction}

Data were stored in a spreadsheet template designed to enable easy cross-reviewer comparison. We collected all relevant outcome data, as well as all study characteristics relevant to outcome interpretation or subanalyses. For each outcome, both the numerator and denominator were recorded (eg, the numbers of patients with polyps and the total study participants). Age- and sex-specific data were ascertained to the extent available.

\section{Statistical Analysis}

Random-effects regression was used to meta-analyze outcome data where possible, and $t$ tests (Wald) were used to examine the differences in outcomes against comparators defined in Supplementary Table 1-first for prevalence by world region, then for other outcomes, including all world regions with prevalence not statistically different from the United States at a standard 5\% significance level. $Q$ and $I^{2}$ statistics were calculated to measure outcome heterogeneity across studies. Bar charts were used with forest plots to visualize meta-analysis results. Linear models and $t$ tests (Wald) were used to examine overall and regionspecific trends in prevalence by calendar year. Log-linear models were fitted for overall and study-specific trends by age.

All analyses were performed using $\mathrm{R}$ statistical software, version 3.6.2 (R Foundation for Statistical Computing, Vienna, Austria).

\section{Results}

\section{Study Selection}

The literature search returned 4462 references through April 19, 2018 (Supplementary Figure 1). After duplicate removal, 2123 studies were selected for review. During abstract review, 1669 irrelevant studies were removed. During full-text review, an additional 380 studies were excluded. In total, 74 studies on serrated polyps were included, of which 69 reported on prevalence ${ }^{28-96}$ and 21 reported on clinical features. $^{28,37,39,47,50,52,55-57,65,67,70,86,88,91,92,97-101}$ of the excluded studies, some were relevant but discarded because of overlap with larger studies from the same source population. ${ }^{102-107}$ For the same reason, specific outcomes for some of the included studies were excluded.

\section{Study Characteristics and Quality Appraisal}

All included studies used colonoscopy in combination with pathology review as the instrument for serrated polyp detection. No autopsy studies were identified. Study setting ranged from community hospital to academic medical center from 4 different world regions: the United States $(\mathrm{n}=$ $36)$, Europe $(n=23)$, Asia $(n=11)$, and Australia $(n=4)$. Although inclusion criteria varied, studies often included examinations for screening or symptoms and excluded patients with a history of polypectomy, CRC, colectomy, familial risk syndromes, inflammatory bowel disease, or a recent colon examination. Generally, the study examinations were performed between 2005 and 2015, diagnostic criteria were based on the WHO classification manual or various earlier sources, mean patient age was approximately 60 years, and the average percentages of female patients was approximately $50 \%-60 \%$. For details, see Supplementary Table 4.

Because study enrollment was nonrandom (based on selection for colonoscopy instead of random sampling of the general population) and outcome assessment is operatordependent (colonoscopy and pathology), ${ }^{49}$ the risk of bias for the included studies was judged to be moderate to high (Supplementary Table 5).

\section{Prevalence of Sessile Serrated Polyps by Study Publication Year and Size}

Few reports on the prevalence of SSPs were published before 2010, but the number of reports increased dramatically after the serrated polyp was first included in the 2010 WHO manual for tumor classification (Supplementary Figure 2). ${ }^{8}$ The range for reported prevalence of SSPs at colonoscopy across all studies was very broad $(0.0 ; 95 \%$ confidence interval [CI], $0.0-0.1$ in Cao et $\mathrm{al}^{40}$ and up to 20.0\%; 95\% CI; 17.3-23.2 in Bettington et $\mathrm{al}^{36}$ ). Despite an increasing awareness of SSPs, there was no significant 
upward trend in reported prevalence over time across all studies $(+0.1 \%$ per year; $95 \%$ CI -0.2 to $0.4 ; P=.49)$. However, trends varied by world region and did increase among US studies specifically $(+0.3 \%$ per year; $95 \%$ CI, $0.0-$ 0.7; $P=.03$ ) (Supplementary Figure 2).

\section{Prevalence of Sessile Serrated Polyps by World Region}

The prevalence of SSPs at colonoscopy in the United States was $5.1 \% \quad(95 \% \quad$ CI, 3.6-6.5) (Supplementary Figures 3 and 4). Prevalence was higher in Australia (10.5\%; 95\% CI, 2.8-18.2; $P=.03$ ) but not statistically different in Asia (2.6\%; 95\% CI, 0-5.9; $P=.14$ ) and Europe (3.9\%; 95\% CI, 2.0-5.9; $P=.51$ ) compared with the United States (Supplementary Figures 3 and 4). Excluding 1 extreme statistical outlier, ${ }^{42}$ the mean prevalence for Asia was statistically different from the United States $0.9 \%$; 95\% CI, 0.5-1.3; $P=.004)$. The pattern in polyp prevalence across regions was qualitatively similar to the reported CRC incidence pattern, ${ }^{14}$ although relative prevalence differences appear larger (Supplementary Figure 3).

The mean overall prevalence of SSPs at colonoscopy across all US and European studies was 4.6\% (95\% CI, 3.45.8) (Figure 1).

The mean fraction of all potentially precancerous polyps with sessile serrated histology in US and European studies was 9.4\% (95\% CI, 6.6-12.3) (Figure 2).

Even within US and European studies there was substantial heterogeneity in estimates, with study-specific prevalences ranging from as low as $0.4 \%$ (95\% CI, $0.0-$ $0.8)^{64}$ to as high as $13.8 \%$ (95\% CI, 9.0-18.6; $Q=1716 ; P<$ .001 ) (Figure 1$)^{68}$ and with the fraction of polyps with sessile serrated histology ranging from 3.9\% (95\% CI, 3.3$4.6)^{37}$ to $25.4 \%$ (95\% CI, 19.5-31.3; $\left.Q=2430, P<.001\right)$ (Figure 2). ${ }^{68}$

\section{Prevalence According to Definition for Clinically Relevant Serrated Polyps}

Under older terminology, the prevalence of clinically relevant serrated polyps in US and European studies varied from 1.8\% (95\% CI, 1.3-2.2) for large hyperplastic polyps to $3.3 \%$ (95\% CI, 1.6-5.0) for serrated adenomas, to $8.5 \%$ (95\% CI, 6.7-10.4) for proximal serrated polyps (Figure 3 and Supplementary Figure 5). The last was significantly higher than the prevalence with the strict SSP definition (4.6\%; 95\% CI, 3.4-5.8; $P<.001$ ).

Under strict terminology, the prevalence of SSPs and traditional serrated adenomas combined (4.4\%; $95 \% \mathrm{CI}$, 2.9-5.9) was somewhat lower than the prevalence of only SSPs (Figure 3), but this difference was not significant $(P=$ .93) and was due to study selection, because not all studies reported on both histologies. The prevalence of SSPs alone in the studies reporting on both SSPs and traditional serrated adenoma was $4.1 \%$ (95\% CI, 2.6-5.5), suggesting a net prevalence for traditional serrated adenomas of approximately $0.3 \%$.

Under more liberal definitions for clinically relevant histology, size, and location, the prevalence estimates were higher than under the strict SSP definition, ranging from 5.6\% (95\% CI, 3.3-7.9; $P=.44$ ) for definitions based primarily on histology and large size to $12.3 \%$ (95\% CI, 9.315.4; $P<.001$ ) for definitions based primarily on histology and proximal location (Figure 3 ).

\section{Prevalence of Sessile Serrated Polyps According to Examination Indication and Quality}

The prevalence of SSPs in US and European studies was not related to examination indication, that is, whether the colonoscopy detecting the polyps was performed for screening in asymptomatic adults vs for screening or other indications $(4.3 \%$; $95 \% \mathrm{CI}, 2.4-6.1$ vs 4.5\%; 95\% CI, 2.9-6.0; $P=.89$ ) (Figure 4 and Supplementary Figure 6). Although prevalence at a patient's initial screening examination was higher $(5.3 \%$; 95\% CI, 0-11.0; $P=.73$ ), this estimate was based on only 3818 examinations from 2 studies with wide confidence intervals (Figure 4).

Prevalence was higher when patients were examined by high polyp detectors or with enhanced endoscopes $(9.1 \%$; 95\% CI, 4.0-14.2 for these high-performance examinations vs $4.7 \%$; $95 \% \mathrm{CI}, 3.5-5.9$ for unselected examinations; $P=$ .04) (Figure 4 and Supplementary Figure 6). Prevalence was also higher for examinations with good to excellent bowel preparation $(8.2 \%$; 95\% CI, 3.3-13.0), although the difference vs all examinations was not significant $(P=.10)$ (Figure 4).

\section{Prevalence of Sessile Serrated Polyps by Age and Sex}

Few US and European studies reported on the prevalence of SSPs by age and sex. The age pattern for SSPs contrasted with that for adenomatous polyps (Figure 5). SSP prevalence increased with age, but the relative increase was smaller than that for adenoma and did not reach statistical significance (relatively, $+1.9 \%$ per age year; $95 \% \mathrm{CI},-0.1-3.9$ for 2 studies providing a denominator; $P=.06$ vs $+2.7 \%$; $95 \% \mathrm{CI}, 2.0-3.3$ for adenomas; $P$ $<.001)$. Across studies, the relative age increases declined over time (Supplementary Figure 7 and Supplementary Tables 6 and 7).

The ratio for the reported prevalence of SSPs in men vs women of 1.20 (4.9\%; 95\% CI, 2.8-7.0 for men vs $4.1 \%$; 95\% CI, 2.7-5.5 for women; $P=.54$ ) (Supplementary Figures 8 and 9) was comparable to the ratio of 1.19 for adenomas (39.9\%; 95\% CI, 31.3-48.6 for men vs 33.4\%, 95\% CI, 25.9-40.8 for women; $P=.35$ ) (Supplementary Table 8).

\section{Number, Size, and Location of Sessile Serrated Polyps}

The number, size, and localization of sessile serrated vs adenomatous polyps in US and European studies is presented in Figure 6.

Compared with adenomatous polyps, SSPs were characterized by a relatively lower multiplicity, with $69.0 \%$ 
Figure 1. The prevalence of SSPs across included studies from the US and European. Squares indicate means, square size represents population size, whiskers show $95 \%$ Cls, and the polygon indicates the pooled mean, random-effects metaregression. ${ }^{\star \star \star}$ Significant heterogeneity $(P<.001)$.

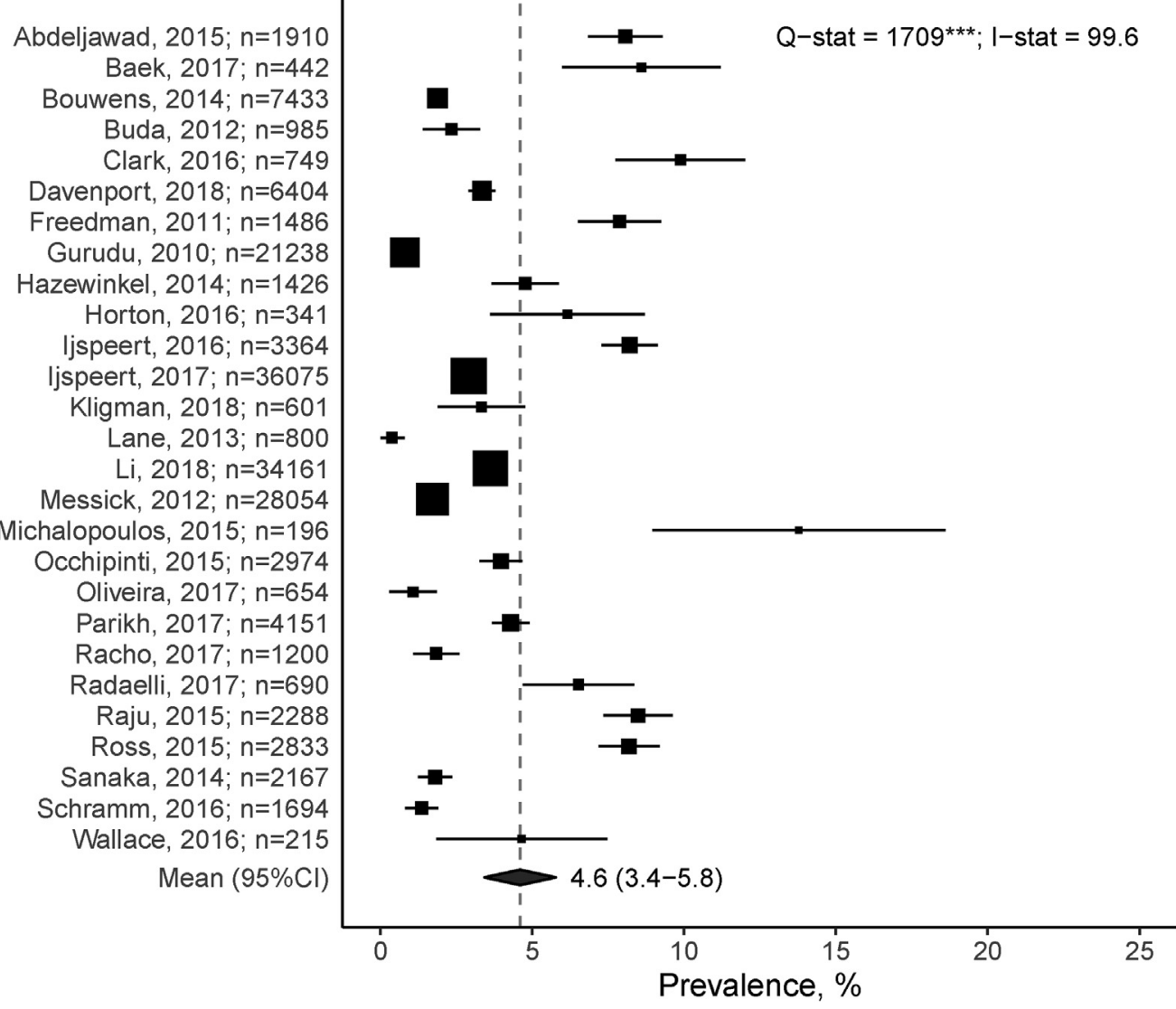

(95\% CI, 45.9-2.1\%; $P=.08$ ) (Supplementary Figure 10) of patients with SSPs vs 43.3\% (95\% CI, 38.0-48.6) (Supplementary Table 9) of patients with adenomas having only 1 polyp and $14.3 \%$ (95\% CI, $0-31.3 ; P=.07)$ vs $34.0 \%$ (95\% CI, 28.0-40.0) of those having 3 or more, respectively.
SSPs were somewhat larger on average than adenomas, with 19.3\% (95\% CI, 12.4-26.2; $P=.13$ ) (Supplementary Figure 11) vs $13.2 \%$ (95\% CI, 10.4-16.1) (Supplementary Table 10) having a diameter of more than $10 \mathrm{~mm}$.

Compared with adenomas, more SSPs were located proximal to the splenic flexure: $71.5 \%$ (95\% CI, 63.5-79.5;

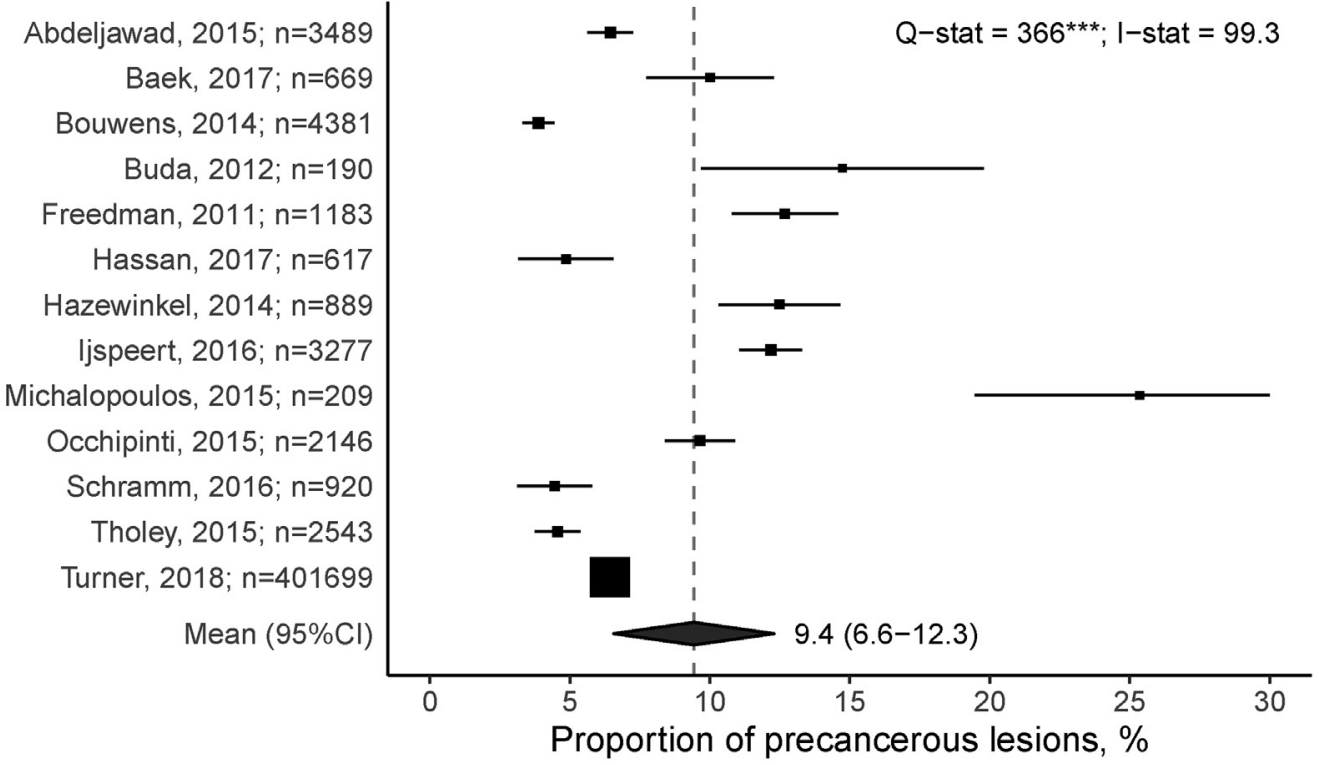

Figure 2. The fraction of polyps with sessile serrated histology across included. US and European studies. Squares indicate means, square size represents population size, whiskers show 95\% Cls, and the polygon indicates the pooled mean, random-effects metaregression. Precancerous lesions include conventional adenoma, SSPs, and traditional serrated adenoma. ${ }^{* \star *}$ Significant heterogeneity $(P<.001)$. 


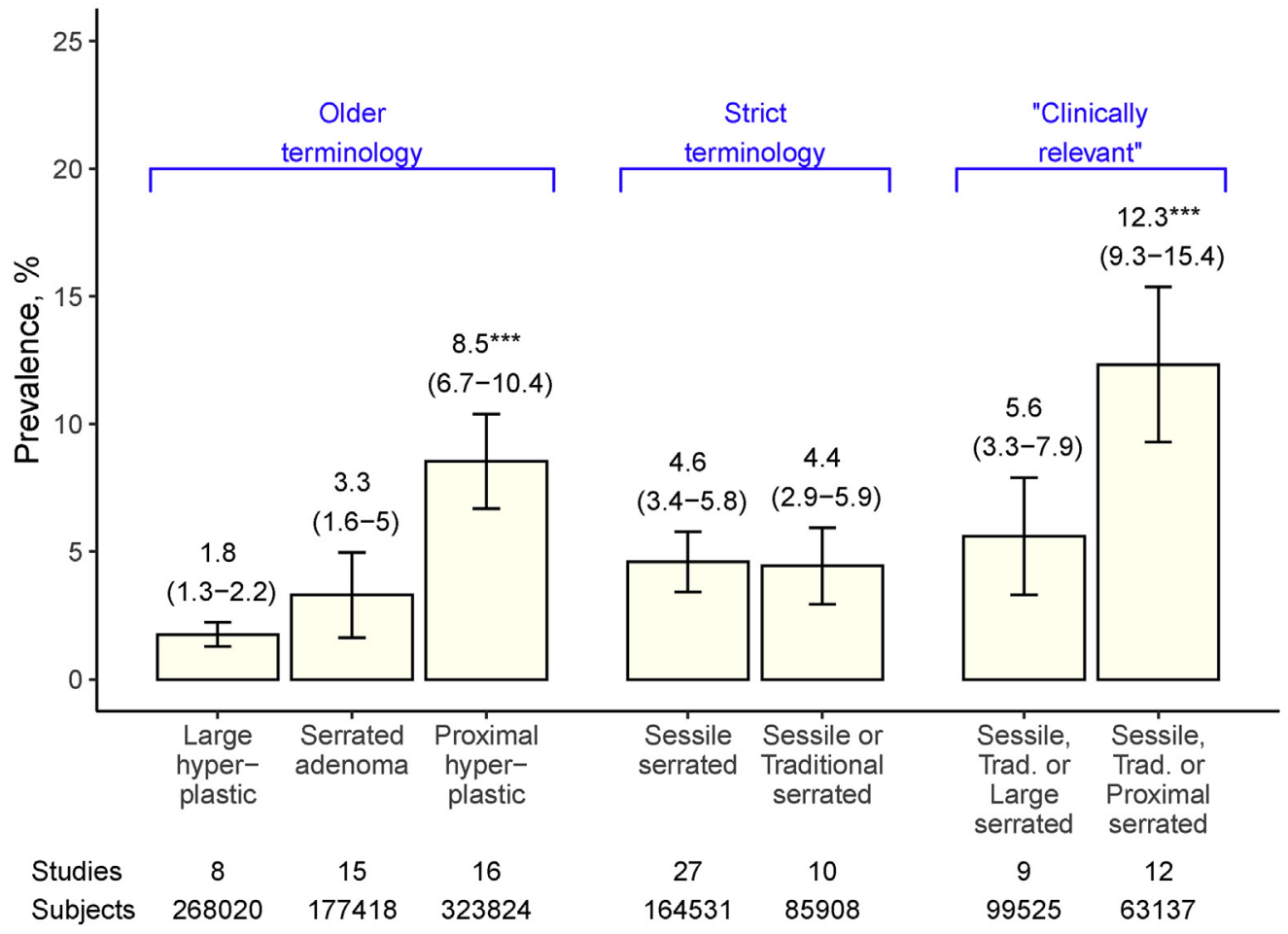

Figure 3. The prevalence of serrated polyps according to clinical definition in US and European studies. Whiskers show 95\% Cls. The clinically relevant grouping includes definitions combining sessile serrated, traditional serrated, and hyperplastic polyps by size ( $>5$ or $>10$ $\mathrm{mm}$ ) and/or location (proximal). See Supplementary Figure 5 for corresponding forest plots and more detail on polyp definitions. ${ }^{* \star *}$ Significant difference vs SSP prevalence $(P<.001)$.
$P=.008)$ (Supplementary Figure 12$)$ vs $59.3 \%(95 \% \mathrm{CI}$, 54.3-64.2) (Supplementary Table 11). The proportion of polyps located in the rectum was similar $(P=.77)$ and less than $10 \%$ for both types of polyps.

\section{Sessile Serrated Polyps and Synchronous Adenoma}

Among 2 studies reporting coexistence of adenomas and SSPs, $49.4 \%$ (95\% CI, 45.4-53.9) of patients with SSPs had adenomas (Supplementary Figure 13), notably more than the average prevalence of adenoma in autopsy studies (Supplementary Figure 8).

\section{Presence and Age at Detection of Cytologic Dysplasia in Sessile Serrated Polyps}

The proportion of SSPs with reported cytologic dysplasia ranged from $3.7 \%$ to $42.9 \%$ across 4 US and 4 European studies (Figure 7), with an overall mean of $13.9 \%$ (95\% CI,
Figure 4. SSP prevalence according to examination indication and quality level in US and European studies. Whiskers show 95\% Cls. *Significant difference vs prevalence in unselected examinations $(P<.05)$. Good-excellent bowel preparation was determined by the Aronchick scale, 7-9 Boston Bowel Preparation Score, or split dose; high-quality examinations indicates enhanced endoscopes or a provider from the upper quartile of SSP detection. See Supplementary Figure 6 for forest plots and definitions.

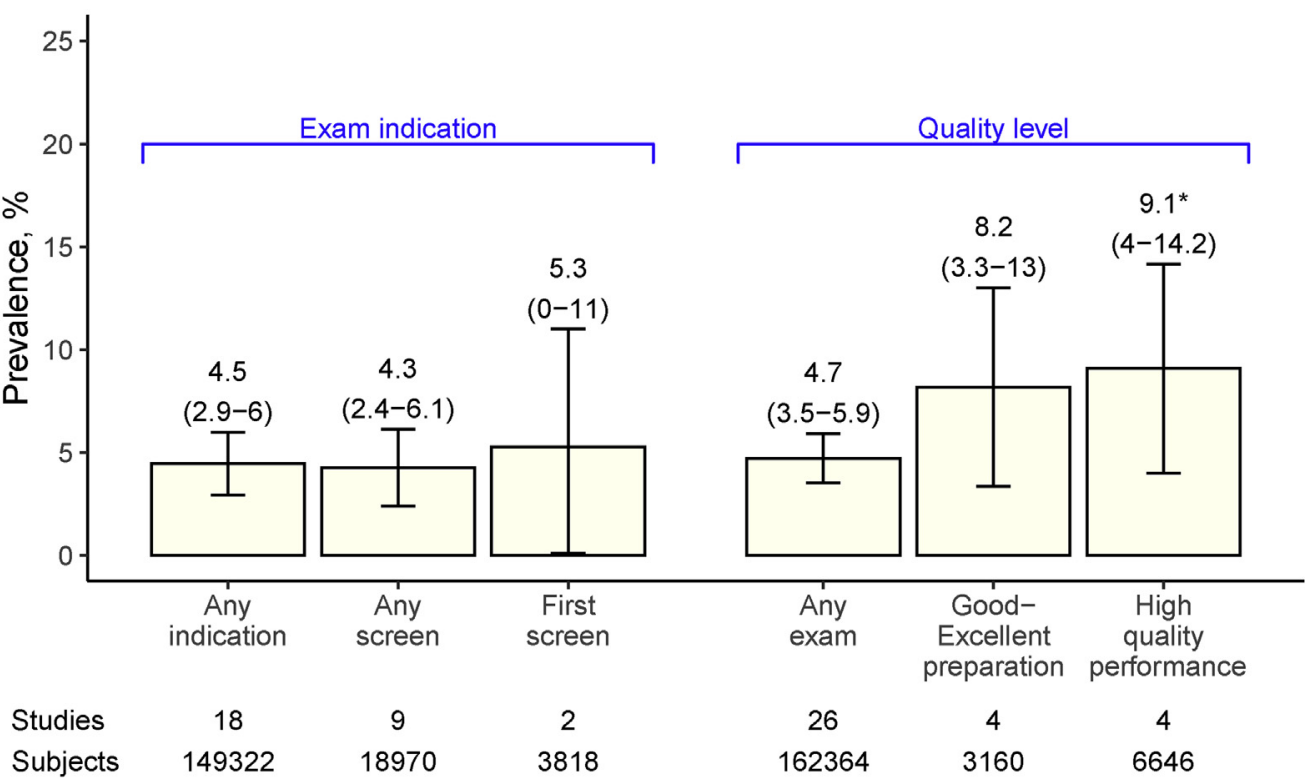


A

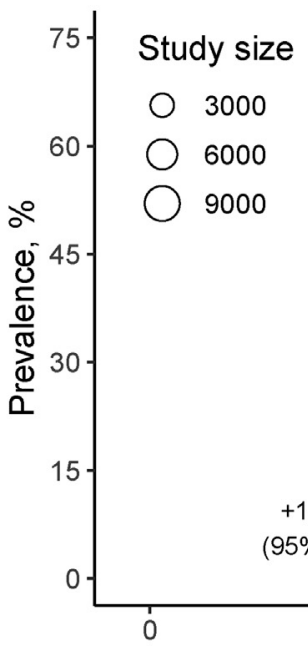

B

Figure 5. The prevalence of $(A)$ sessile serrated vs (B) adenomatous polyps by age. Dots represent study observations by age, colors indicate the different US and European studies (Supplementary Tables 6 and 7), size shows patient denominator, and the dashed line is fitted log-linear trend for ages 40-100 years, measuring relative increase by age-year. Some studies in $A$ provided no patient denominator and were excluded from trends and represented with small constant numbers. ${ }^{* \star}$ Significant trend $(P<.001)$.

\section{Sessile serrated polyps}

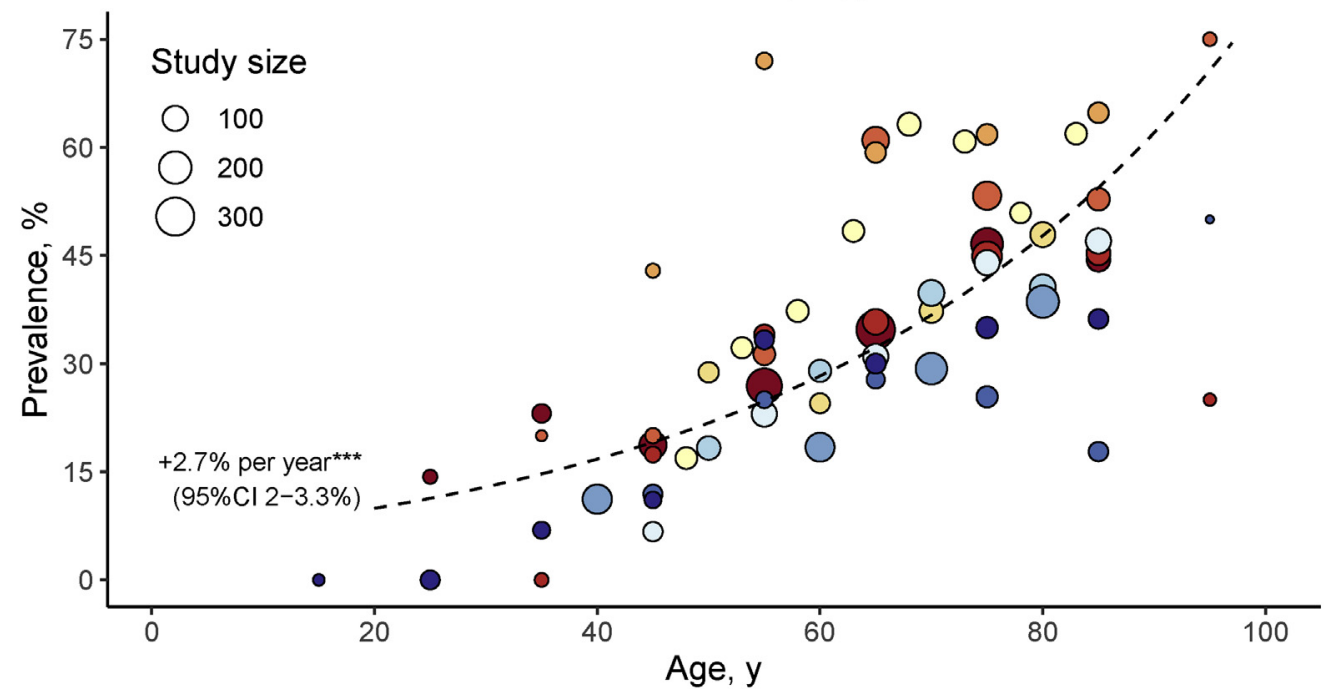

4.8-23.0). Although both US and European studies consisted of a mix of studies including examinations for screening or other indications (Supplementary Table 4), the proportion of SSPs with cytologic dysplasia differed between US and European studies $(7.8 \%$; $95 \% \mathrm{CI}, 2.9-12.6$ vs $20.6 \%$, $95 \%$ CI, 3.6-37.5; $P=.15$ ) (Supplementary Figure 3), possibly due to relatively more nonscreening examinations in Europe (Supplementary Table 12). Excluding 1 extreme statistical outlier, ${ }^{37}$ the proportion of SSPs with dysplasia decreased to 9.7\% (95\% CI, 4.5-14.9).

SSPs with dysplasia tended to be reported at higher ages than SSPs without dysplasia (Supplementary Figure 14 and Supplementary Table 13). Among 4 US and European studies reporting age at diagnosis, SSPs without dysplasia were detected at an average age of 60.8 years, SSPs with low-grade or any dysplasia at an average age of 65.6 years, and SSPs with high-grade dysplasia at an average age of 70.2 years.

\section{Discussion}

We performed a systematic review including metaanalysis of studies published since 2000 on the prevalence and clinical features of SSPs to provide perspective into the potential importance of these lesions. The overall prevalence of SSPs in colonoscopy studies varied around the world. In studies from the United States and Europe, based on strict histologic definitions, the prevalence was $4.6 \%$ (95\% CI, 3.4-5.8), and SSPs accounted for 9.4\% (95\% CI, 6.6-12.3) of potentially precancerous lesions. Prevalence estimates were as high as $9.1 \%$ when based on high-quality colonoscopy examinations and $12.3 \%$ when also counting potentially clinically relevant hyperplastic polyps. Compared with adenomas, SSPs more often presented solitary, with large size and in the proximal colon. SSPs with dysplasia and high-grade dysplasia were reported at approximately 5 and 10 years older average ages, respectively, than nondysplastic SSPs. 
A Number - Sessile serrated polyps
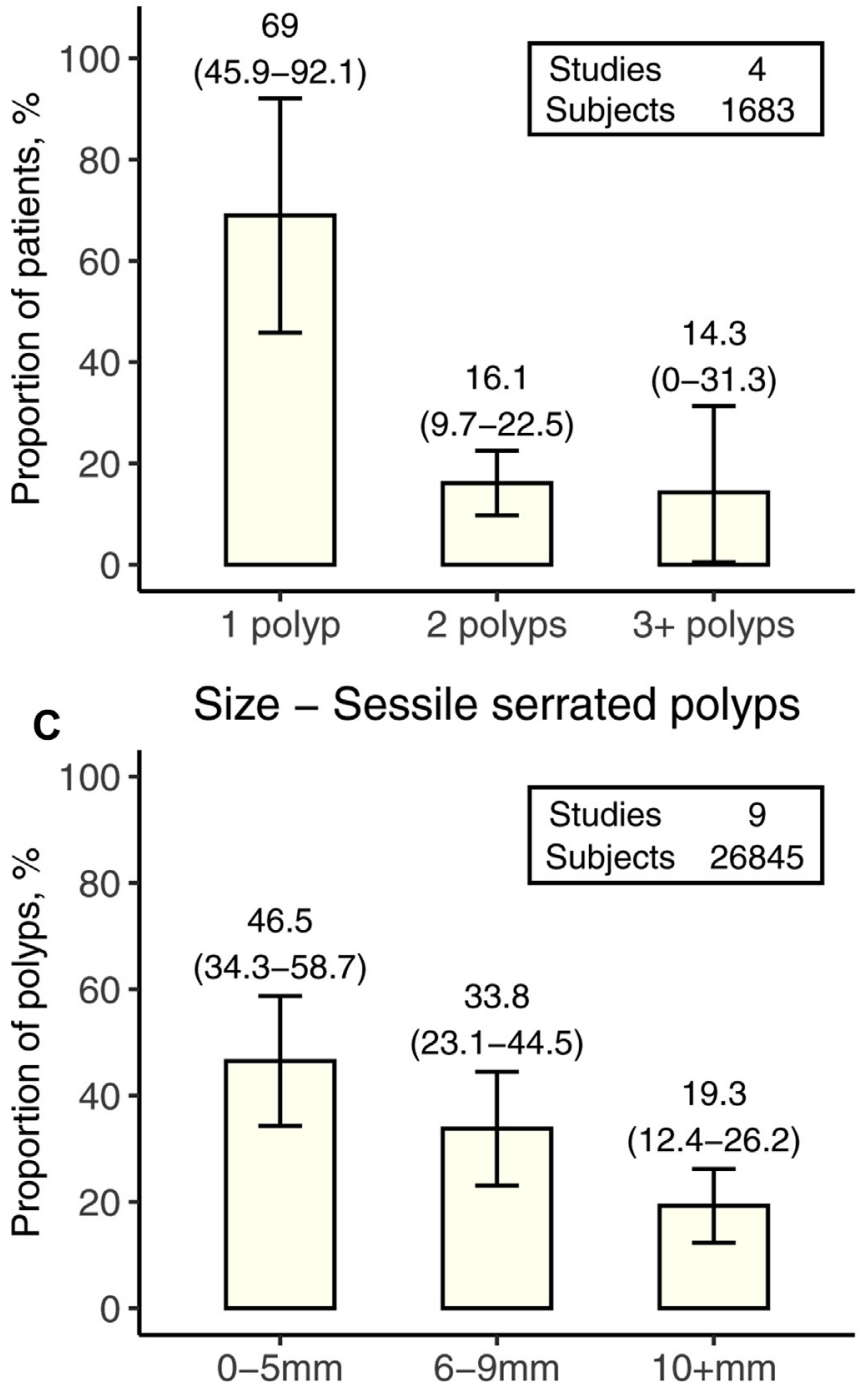

E Location - Sessile serrated polyps

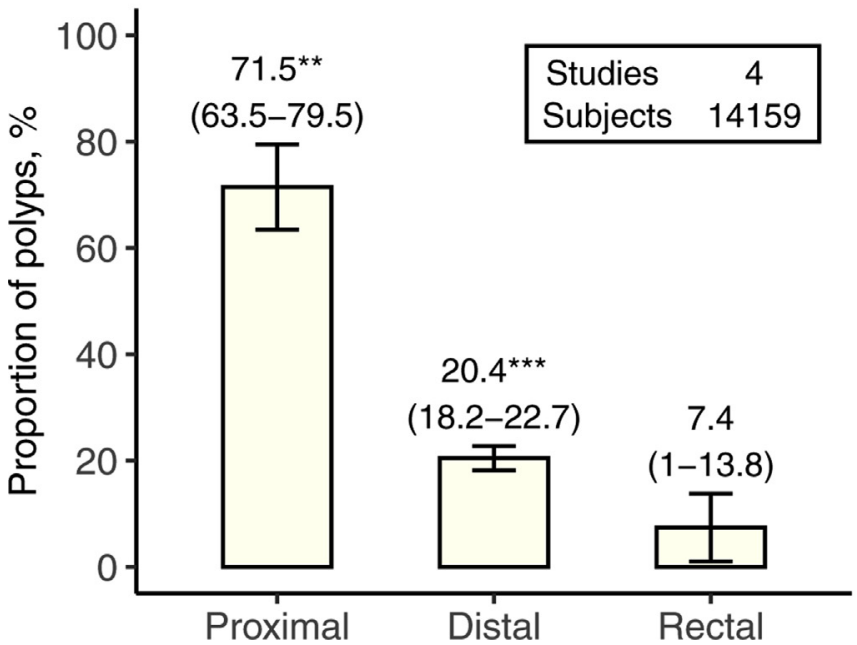

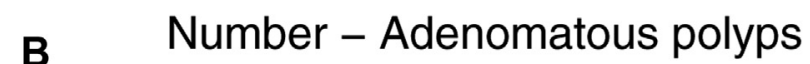

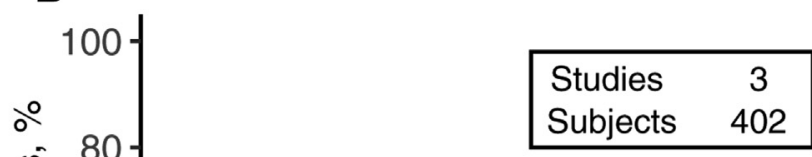

43.3

(38-48.6) 34

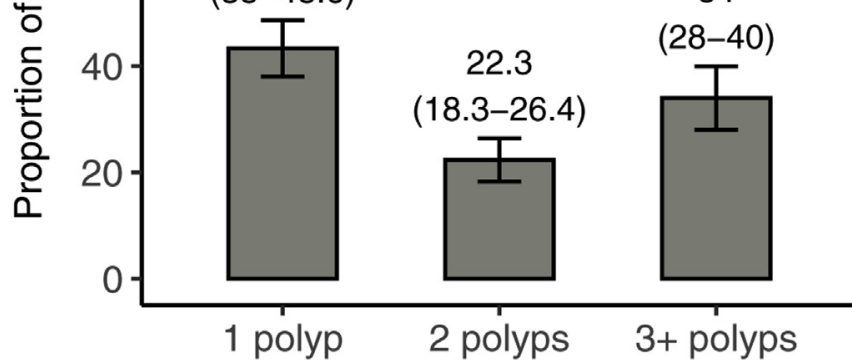

D Size - Adenomatous polyps

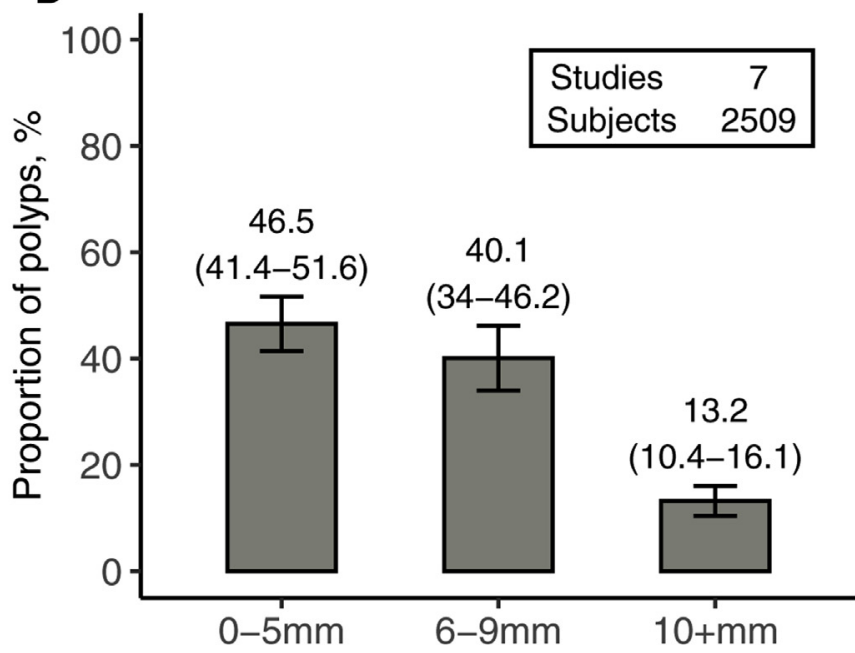

F $\quad$ Location - Adenomatous polyps

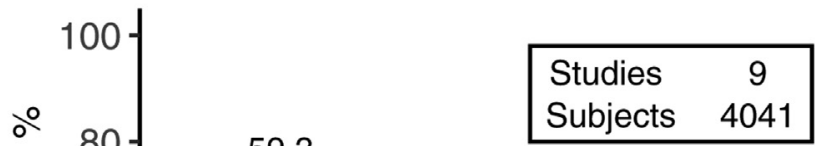

32.1

(29.3-35)

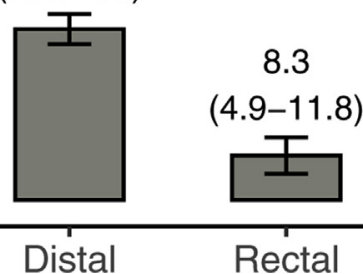

Figure 6. The $(A, B)$ number, $(C, D)$ size, and $(E, F)$ localization of $(A, C, E)$ sessile serrated vs $(A, B, F)$ adenomatous polyps. US and European studies. See Supplementary Figures 10-12 for forest plots and Supplementary Tables 9-11 for adenoma data. Whiskers show 95\% Cls. Significant differences for SSP vs adenoma: ${ }^{\star \star} P<.01 ;{ }^{\star \star \star} P<.001$. Sizes were small $(0-5 \mathrm{~mm})$, medium (6-9 mm), or large (10+ $\mathrm{mm})$; location was proximal (cecum, ascending colon, hepatic flexure, transverse colon), distal (splenic flexure, descending colon, sigmoid colon), or rectal. 


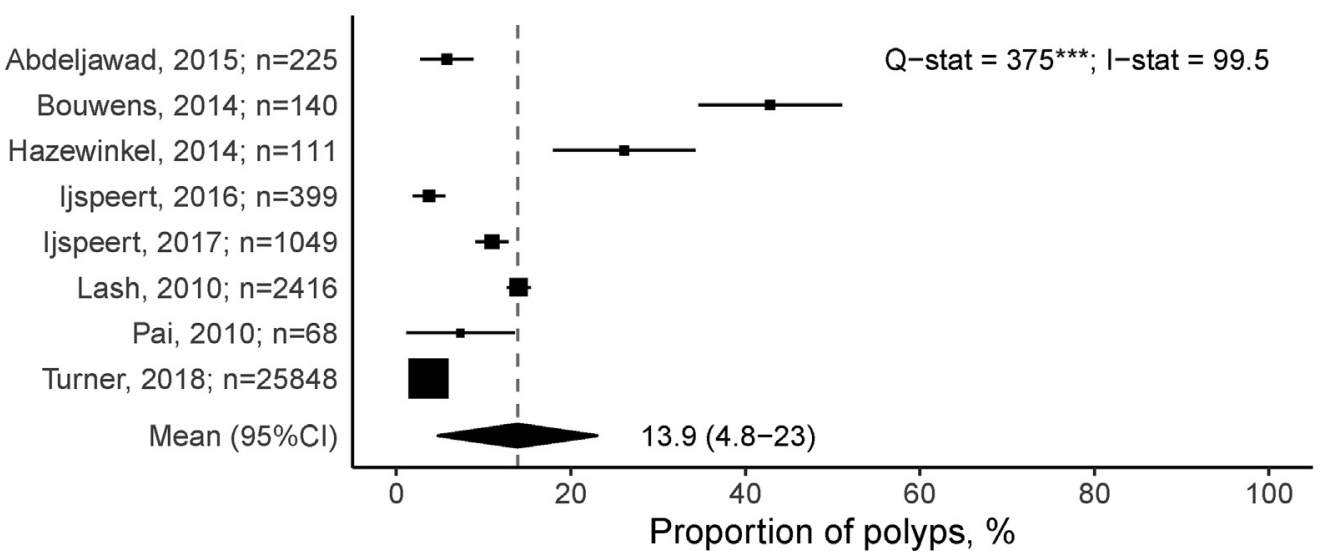

Figure 7. The proportion of SSPs with cytological dysplasia across studies. US and European studies, including nonscreening indications. Squares indicate means, square size represents population size, whiskers show 95\% Cls, and the polygon indicates the pooled mean, random-effects metaregression. US, 7.8\% (95\% Cl, 2.9-12.6) vs European studies, $20.6 \%$ (95\% Cl, 3.6-37.5) $(P=.15)$. For some studies, the relative prevalence of dysplastic vs all SSPs was used as an approximation (Supplementary Table 12). Excluding 1 outlier, ${ }^{37}$ the proportion decreased to $9.7 \%$ (95\% Cl, 4.5-14.9); Europe: 13.1\% (95\% $\mathrm{Cl}, 0.6-25.5) .{ }^{\star \star \star}$ Significant heterogeneity $(P<.001)$.

There is no consensus in the literature on which serrated polyps are clinically relevant, and this has consequences for the estimates of prevalence and risk. Histologically, SSPs and hyperplastic polyps may be difficult to distinguish, ${ }^{49,53}$ creating the potential for misclassification under strict histologic definitions that consider SSPs and traditional serrated adenomas as the only clinically relevant serrated polyps. ${ }^{8}$ More liberal definitions have been proposed to address this, but studies differ on whether these should include large, ${ }^{33,57,89}$ proximal, $^{59,81}$ or both large and proximal hyperplastic polyps. ${ }^{32,78,97}$ We report separate results based on older terminology, strict definitions, and more liberal definitions to shed light on what can be a confusing subject.

We found no significant association between SSP detection and calendar year when all studies were pooled. However, lower SSP rates in Asia, including in large recent studies, affected the pooled estimates. Among US studies, there was a significant upward trend $(+0.3 \%$ point/year $)$, consistent with reports from specific settings. ${ }^{53,65}$ Differences in prevalence between Asia and the United States may be due to practice variation or more fundamental causes. The lower reported SSP rates in Asia are consistent with CRC incidence data (Supplementary Figure 3B) and race-specific data from the United States. ${ }^{65}$ Further research on these differences could help elucidate SSP etiology.

SSP prevalence increased with age, but the increases did not quite meet the traditional criteria for statistical significance, unlike increases for adenoma. The relationship between SSP prevalence and age may have evolved over time by period or cohort effects (Supplementary Figure 7), such as more prior colonoscopies with polypectomy in older patients or an increased risk of SSPs in younger adults. An increased risk in younger persons would synchronize with documented young-onset CRC increases, ${ }^{108}$ although those increases were mostly confined to the rectum, where SSPs are uncommon.
Prevalence was not associated with symptomatic indications. This is consistent with previous studies ${ }^{65,109}$ and suggests SSPs may cause fewer symptoms than adenomas.

There was substantial heterogeneity in SSP prevalence across studies, which may be partly due to study biases. Studies included in this review were judged to have moderate to high risk of bias due to patient selection, detection bias, and possible misclassification. No studies ascertained unselected samples from the general population. In the United States, undergoing a colonoscopy is associated with socioeconomic indicators, such as health literacy and insurance status. ${ }^{110}$ Patients with a previous screening history were usually included, which could be associated with lower SSP prevalence either due to polypectomy earlier in life or selection of healthy individuals if patients with a polypectomy earlier in life were excluded (Figure 5). Although colonoscopy is the criterion standard for colon examination, it may have missed a substantial proportion of serrated polyps (Figure 4), ${ }^{111}$ particularly in earlier years (Supplementary Figure 2). Thus, the true prevalence of serrated polyps should be considered higher than what is reported in colonoscopy studies, because it must be corrected by the miss rate. Finally, it may be difficult for pathologists to distinguish sessile serrated from hyperplastic polyps. Both the endoscopic detection and pathology assessment of SSPs require training and verification of quality to ensure adequate diagnosis.

Dysplasia occurred in $3.7 \%-42.9 \%$ of SSPs across studies in our review. This wide range must be interpreted with caution (Supplementary Table 12). It may reflect small sample sizes, population differences in risk behavior (eg, smoking), or the presence of symptoms signaling dysplastic but not nondysplastic SSPs. Further research should determine the true prevalence of dysplastic SSPs in unselected populations and the effect of risk factors including smoking.

Strengths of this study include the systematic character, the sensitive search strategy, and the broad scope encompassing many relevant questions regarding SSP 
epidemiology. The study also has limitations. First, we did not attempt to reclassify hyperplastic polyps from the era before awareness of SSPs. ${ }^{112}$ Although this might reduce the risk of detection bias and contamination, it is not feasible to perform histopathology reassessment of all specimens in these older studies. Few of the reviewed autopsy studies provided detailed information on hyperplastic polyps. Second, although our review addressed several questions related to SSP risk, such as regarding the size and presence of dysplasia, we could not directly assess the risk of malignancy. Our literature search suggests that very few studies with longitudinal patient follow-up exist. A large trial following patients after SSP removal is recruiting, but results are not expected for $>10$ years, $^{113}$ and there is no plan to observe SSPs unresected. Observational data suggest no higher postpolypectomy risk for SSPs vs adenomas, whereas features such as large size and dysplasia, which we estimated to each occur in up to $10 \%-15 \%$ of SSPs, may increase risk. $^{114-116}$

In conclusion, although SSP prevalence may be underestimated by colonoscopy studies with inherent miss rates, SSPs appear to be relatively uncommon compared with adenomas. More standardized diagnostic criteria for clinically relevant serrated polyps, training, and quality verification for endoscopists and pathologists are needed to ensure SSP detection and removal. Additional research is needed to increase clarity on actual prevalence by age, variation across settings, and long-term risk with and without removal.

\section{Supplementary Material}

Note: To access the supplementary material accompanying this article, visit the online version of Gastroenterology at www.gastrojournal.org, and at https://doi.org/10.1053/ j.gastro.2020.03.025.

\section{References}

1. Siegel RL, Miller KD, Fedewa SA, et al. Colorectal cancer statistics, 2017. CA Cancer J Clin 2017;67:177-193.

2. Strum WB. Colorectal adenomas. N Engl J Med 2016; 375:389-390.

3. Muto T, Bussey HJ, Morson BC. The evolution of cancer of the colon and rectum. Cancer 1975;36:2251-2270.

4. Morson BC. The evolution of colorectal carcinoma. Clin Radiol 1984;35:425-431.

5. Winawer SJ, Zauber AG, Ho MN, et al. Prevention of colorectal cancer by colonoscopic polypectomy. The National Polyp Study Workgroup. N Engl J Med 1993; 329:1977-1981.

6. Longacre TA, Fenoglio-Preiser CM. Mixed hyperplastic adenomatous polyps/serrated adenomas. A distinct form of colorectal neoplasia. Am J Surg Pathol 1990; 14:524-537.

7. Torlakovic E, Skovlund E, Snover DC, et al. Morphologic reappraisal of serrated colorectal polyps. Am J Surg Pathol 2003;27:65-81.
8. Bosman FT, Carneiro F, Hruban RH, et al. WHO classification of tumours of the digestive system. Geneva, Switzerland: WHO Press, 2010.

9. Lieberman DA, Rex DK, Winawer SJ, et al. Guidelines for colonoscopy surveillance after screening and polypectomy: a consensus update by the US Multi-Society Task Force on Colorectal Cancer. Gastroenterology 2012;143:844-857.

10. Abdeljawad K, Vemulapalli KC, Kahi CJ, et al. Sessile serrated polyp prevalence determined by a colonoscopist with a high lesion detection rate and an experienced pathologist. Gastrointest Endosc 2015;81:517-524.

11. Sweetser S, Jones A, Smyrk TC, et al. Sessile serrated polyps are precursors of colon carcinomas with deficient DNA mismatch repair. Clin Gastroenterol Hepatol 2016; 14:1056-1059.

12. Nishihara R, Wu K, Lochhead $P$, et al. Long-term colorectal-cancer incidence and mortality after lower endoscopy. N Engl J Med 2013;369:1095-1105.

13. Guinney J, Dienstmann R, Wang X, et al. The consensus molecular subtypes of colorectal cancer. Nat Med 2015; 21:1350.

14. Ferlay J, Soerjomataram I, Dikshit R, et al. Cancer incidence and mortality worldwide: sources, methods and major patterns in GLOBOCAN 2012. Int J Cancer 2015; 136(5):E359-E386.

15. CISNET) ClaSMN. Colorectal cancer models overview. Volume 2017.

16. Arminski TC, McLean DW. Incidence and distribution of adenomatous polyps of the colon and rectum based on 1,000 autopsy examinations. Dis Colon Rectum 1964; 7:249-261.

17. Blatt LJ. Polyps of the colon and rectum: incidence and distribution. Dis Colon Rectum 1961;4:277-282.

18. Bombi JA. Polyps of the colon in Barcelona, Spain. An autopsy study. Cancer 1988;61:1472-1476.

19. Chapman I. Adenomatous polypi of large intestine: incidence and distribution. Ann Surg 1963;157:223-226.

20. Clark JC, Collan Y, Eide TJ, et al. Prevalence of polyps in an autopsy series from areas with varying incidence of large-bowel cancer. Int J Cancer 1985;36:179-186.

21. Eide TJ, Stalsberg H. Polyps of the large intestine in northern Norway. Cancer 1978;42:2839-2848.

22. Jass JR, Young PJ, Robinson EM. Predictors of presence, multiplicity, size and dysplasia of colorectal adenomas. A necropsy study in New Zealand. Gut 1992; 33:1508-1514.

23. Rickert RR, Auerbach O, Garfinkel L, et al. Adenomatous lesions of the large bowel: an autopsy survey. Cancer 1979;43:1847-1857.

24. Stemmermann GN, Yatani R. Diverticulosis and polyps of the large intestine. A necropsy study of Hawaii Japanese. Cancer 1973;31:1260-1270.

25. Vatn $\mathrm{MH}$, Stalsberg $\mathrm{H}$. The prevalence of polyps of the large intestine in Oslo: an autopsy study. Cancer 1982; 49:819-825.

26. Williams AR, Balasooriya BA, Day DW. Polyps and cancer of the large bowel: a necropsy study in Liverpool. Gut 1982;23:835-842. 
27. Hoy D, Brooks P, Woolf A, et al. Assessing risk of bias in prevalence studies: modification of an existing tool and evidence of interrater agreement. J Clin Epidemiol 2012; 65:934-939.

28. Abdeljawad K, Vemulapalli KC, Kahi CJ, et al. Sessile serrated polyp prevalence determined by a colonoscopist with a high lesion detection rate and an experienced pathologist. Gastrointest Endosc 2015; $81: 517-524$.

29. Adike A, Buras MR, Gurudu SR, et al. Is the level of cleanliness using segmental Boston bowel preparation scale associated with a higher adenoma detection rate? Ann Gastroenterol 2018;31:217-223.

30. Álvarez C, Andreu M, Castells A, et al. Relationship of colonoscopy-detected serrated polyps with synchronous advanced neoplasia in average-risk individuals. Gastrointest Endosc 2013;78:333-341.

31. Anderson JC, Butterly LF, Goodrich M, et al. Differences in detection rates of adenomas and serrated polyps in screening versus surveillance colonoscopies, based on the New Hampshire Colonoscopy Registry. Clin Gastroenterol Hepatol 2013;11:1308-1312.

32. Anderson JC, Baron JA, Ahnen DJ, et al. Factors associated with shorter colonoscopy surveillance intervals for patients with low-risk colorectal adenomas and effects on outcome. Gastroenterol 2017;152:1933-1943.

33. Anderson JC, Butterly LF, Weiss JE, et al. Providing data for serrated polyp detection rate benchmarks: an analysis of the New Hampshire Colonoscopy Registry. Gastrointest Endosc 2017;85:1188-1194.

34. Aniwan S, Ratanachu-Ek T, Pongprasobchai S, et al. Impact of fecal $\mathrm{Hb}$ levels on advanced neoplasia detection and the diagnostic miss rate for colorectal cancer screening in high-risk vs. average-risk subjects: a multi-center study. Clin Transl Gastroenterol 2017; 8(8):e113.

35. Baek MD, Jackson CS, Lunn J, et al. Endocuff-assisted colonoscopy significantly increases sessile serrated adenoma detection in veterans. J Gastrointest Oncol 2017;8:636-642.

36. Bettington M, Walker N, Rahman T, et al. High prevalence of sessile serrated adenomas in contemporary outpatient colonoscopy practice. Intern Med J 2017; 47:318-323.

37. Bouwens MWE, Van Herwaarden YJ, Winkens B, et al. Endoscopic characterization of sessile serrated adenomas/polyps with and without dysplasia. Endoscopy 2014;46:225-235.

38. Bretagne JF, Hamonic S, Piette C, et al. Interendoscopist variability in proximal colon polyp detection is twice higher for serrated polyps than adenomas. World J Gastroenterol 2016;22:8549-8557.

39. Buda A, De Bona M, Dotti I, et al. Prevalence of different subtypes of serrated polyps and risk of synchronous advanced colorectal neoplasia in average-risk population undergoing first-time colonoscopy. Clin Transl Gastroenterol 2012;3:e6.

40. Cao HL, Chen X, Du SC, et al. Detection rate, distribution, clinical and pathological features of colorectal serrated polyps. Chin Med J (Engl) 2016;129:2427-2433.
41. Chen $Y, Y u$ J, Liu $Y$, et al. Increasing detection rate of proximal serrated polyps in a large hospital of China over a 10-year period. Int J Clin Exp Med 2016;9:1274512750.

42. Cheng CL, Kuo YL, Liu NJ, et al. Impact of bowel preparation with low-volume (2-liter) and intermediatevolume (3-liter) polyethylene glycol on colonoscopy quality: a prospective observational study. Digestion 2015;92:156-164.

43. Clark BT, Laine L. High-quality bowel preparation is required for detection of sessile serrated polyps. Clin Gastroenterol Hepatol 2016;14:1155-1162.

44. Davenport JR, Su T, Zhao Z, et al. Modifiable lifestyle factors associated with risk of sessile serrated polyps, conventional adenomas and hyperplastic polyps. Gut 2018;67:456-465.

45. de Wijkerslooth TR, Stoop EM, Bossuyt PM, et al. Differences in proximal serrated polyp detection among endoscopists are associated with variability in withdrawal time. Gastrointest Endosc 2013;77:617-623.

46. Fantry LE, Nowak RG, Fisher LH, et al. Colonoscopy findings in HIV-infected men and women from an urban U.S. cohort compared with non-HIV-infected men and women. AIDS Res Hum Retroviruses 2016;32:860-867.

47. Freedman JS, Harari DY, Bamji ND, et al. The detection of premalignant colon polyps during colonoscopy is stable throughout the workday. Gastrointest Endosc 2011;73:1197-1206.

48. Glazer E, Golla V, Forman R, et al. Serrated adenoma is a risk factor for subsequent adenomatous polyps. Dig Dis Sci 2008;53:2204-2207.

49. Gourevitch RA, Rose S, Crockett SD, et al. Variation in pathologist classification of colorectal adenomas and serrated polyps. Am J Gastroenterol 2018;113:431-439.

50. Gurudu SR, Heigh RI, de Petris G, et al. Sessile serrated adenomas: demographic, endoscopic and pathological characteristics. World J Gastroenterol 2010;16:34023405.

51. Hassan C, Senore C, Radaelli F, et al. Full-spectrum (FUSE) versus standard forward-viewing colonoscopy in an organised colorectal cancer screening programme. Gut 2017;66:1949-1955.

52. Hazewinkel Y, De Wijkerslooth TR, Stoop EM, et al. Prevalence of serrated polyps and association with synchronous advanced neoplasia in screening colonoscopy. Endoscopy 2014;46:219-224.

53. Hetzel JT, Huang CS, Coukos JA, et al. Variation in the detection of serrated polyps in an average risk colorectal cancer screening cohort. Am J Gastroenterol 2010; 105:2656-2664.

54. Horton N, Garber A, Hasson H, et al. Impact of singlevs. split-dose low-volume bowel preparations on bowel movement kinetics, patient inconvenience, and polyp detection: a prospective trial. Am J Gastroenterol 2016; 111:1330-1337.

55. Ijspeert JEG, Van Doorn SC, Van Der Brug YM, et al. The proximal serrated polyp detection rate is an easy-tomeasure proxy for the detection rate of clinically relevant serrated polyps. Gastrointest Endosc 2015;82:870877. 
56. ljspeert JEG, De Wit K, Van Der Vlugt M, et al. Prevalence, distribution and risk of sessile serrated adenomas/ polyps at a center with a high adenoma detection rate and experienced pathologists. Endoscopy 2016;48:740746.

57. ljspeert JEG, Bevan R, Senore C, et al. Detection rate of serrated polyps and serrated polyposis syndrome in colorectal cancer screening cohorts: a European overview. Gut 2017;66:1225-1232.

58. Imler TD, Morea J, Kahi C, et al. Multi-center colonoscopy quality measurement utilizing natural language processing. Am J Gastroenterol 2015;110:543-552.

59. Kahi CJ, Li X, Eckert GJ, et al. High colonoscopic prevalence of proximal colon serrated polyps in averagerisk men and women. Gastrointest Endosc 2012;75:515520.

60. Kahi CJ, Vemulapalli KC, Snover DC, et al. Findings in the distal colorectum are not associated with proximal advanced serrated lesions. Clin Gastroenterol Hepatol 2015;13:345-351.

61. Kim HY, Kim SM, Seo JH, et al. Age-specific prevalence of serrated lesions and their subtypes by screening coIonoscopy: a retrospective study. BMC Gastroenterol 2014;14:82.

62. Kligman E, Li W, Eckert GJ, Kahi C. Adenoma detection rate in asymptomatic patients with positive fecal immunochemical tests. Dig Dis Sci 2018;63:11671172.

63. Kumbhari V, Behary J, Hui JM. Prevalence of adenomas and sessile serrated adenomas in Chinese compared with Caucasians. J Gastroenterol Hepatol 2013;28:608612.

64. Lane DS, Messina CR, Cavanagh MF, et al. Delivering colonoscopy screening for low-income populations in Suffolk County strategies, outcomes, and benchmarks. Cancer 2013;119:2842-2848.

65. Li D, Woolfrey J, Jiang SF, et al. Diagnosis and predictors of sessile serrated adenoma after educational training in a large, community-based, integrated healthcare setting. Gastrointest Endosc 2018;87:688694.

66. Lieberman D, Moravec M, Holub J, et al. Polyp size and advanced histology in patients undergoing colonoscopy screening: implications for CT colonography. Gastroenterology 2008;135:1100-1105.

67. Messick CA, Church J, Bennett A, et al. Serrated polyps: new classifications highlight clinical importance. Colorectal Dis 2012;14:1328-1337.

68. Michalopoulos G, Vrakas S, Ntouli V, et al. Sessile serrated adenomas versus conventional adenomas. Different polyps in different populations? Indian J Gastroenterol 2015;34:245-251.

69. Ng SC, Ching JYL, Chan VCW, et al. Association between serrated polyps and the risk of synchronous advanced colorectal neoplasia in average-risk individuals. Aliment Pharmacol Ther 2015;41:108-115.

70. Occhipinti P, Saettone S, Cristina S, et al. Correlation between adenoma and serrated lesion detection rates in an unselected outpatient population. Dig Liver Dis 2015; 47:508-511.
71. Ohki D, Tsuji Y, Shinozaki T, et al. Sessile serrated adenoma detection rate is correlated with adenoma detection rate. World J Gastrointest Oncol 2018;10:8290.

72. Oliveira Ferreira A, Fidalgo C, Palmela C, et al. Adenoma detection rate: I will show you mine if you show me yours. GE Port J Gastroenterol 2017;24:61-67.

73. Parikh MP, Muthukuru S, Jobanputra Y, et al. Proximal sessile serrated adenomas are more prevalent in Caucasians, and gastroenterologists are better than nongastroenterologists at their detection. Gastroenterol Res Pract 2017;2017:6710931.

74. Payne SR, Church TR, Wandell M, et al. Endoscopic detection of proximal serrated lesions and pathologic identification of sessile serrated adenomas/polyps vary on the basis of center. Clin Gastroenterol Hepatol 2014; 12:1119-1126.

75. Pezzoli A, Matarese V, Rubini M, et al. Colorectal cancer screening: results of a 5-year program in asymptomatic subjects at increased risk. Dig Liver Dis 2007;39:33-39.

76. Pohl J, Schneider A, Vogell H, et al. Pancolonic chromoendoscopy with indigo carmine versus standard colonoscopy for detection of neoplastic lesions: a randomised two-centre trial. Gut 2011; 60:485-490.

77. Pyo JH, Ha SY, Hong SN, et al. Identification of risk factors for sessile and traditional serrated adenomas of the colon by using big data analysis. J Gastroenterol Hepatol 2018;33:1039-1046.

78. Racho RG, Krishna M, Coe SG, et al. Impact of an endoscopic quality improvement program focused on adenoma detection on sessile serrated adenoma/polyp detection. Dig Dis Sci 2017;62:1464-1471.

79. Radaelli F, Paggi S, Hassan C, et al. Split-dose preparation for colonoscopy increases adenoma detection rate: a randomised controlled trial in an organised screening programme. Gut 2017;66:270-277.

80. Raju GS, Lum PJ, Slack RS, et al. Natural language processing as an alternative to manual reporting of colonoscopy quality metrics. Gastrointest Endosc 2015; 82:512-519.

81. Raju GS, Vadyala V, Slack R, et al. Adenoma detection in patients undergoing a comprehensive colonoscopy screening. Cancer Med 2013;2:391-402.

82. Riverso M, Perbtani YB, JJD Shuster, et al. Carbon dioxide insufflation is associated with increased serrated polyp detection rate when compared to room air insufflation during screening colonoscopy. Endosc Int Open 2017;5(9):E905-E912.

83. Rodríguez-D’Jesús A, Saperas E. Enhanced flat adenoma detection rate with high definition colonoscopy plus i-scan for average-risk colorectal cancer screening. Rev Esp Enferm Dig 2016;108:257-262.

84. Ross WA, Thirumurthi S, Lynch PM, et al. Detection rates of premalignant polyps during screening colonoscopy: time to revise quality standards? Gastrointest Endosc 2015;81:567-574.

85. Rotondano G, Bianco MA, Cipolletta L, et al. Prevalence and characteristics of serrated lesions of the colorectum 
in Italy: a multicentre prospective cohort study. Dig Liver Dis 2015;47:512-517.

86. Sanaka MR, Gohel T, Podugu A, et al. Adenoma and sessile serrated polyp detection rates: variation by patient sex and colonic segment but not specialty of the endoscopist. Dis Colon Rectum 2014;57:1113-1119.

87. Sano W, Fujimori T, Ichikawa K, et al. Clinical and endoscopic evaluations of sessile serrated adenoma/ polyps with cytological dysplasia. J Gastroenterol Hepatol 2018;33:1454-1460.

88. Schramm C, Kaiser M, Drebber U, et al. Factors associated with reclassification of hyperplastic polyps after pathological reassessment from screening and surveillance colonoscopies. Int J Colorectal Dis 2016;31:319325.

89. Schreiner MA, Weiss DG, Lieberman DA. Proximal and large hyperplastic and nondysplastic serrated polyps detected by colonoscopy are associated with neoplasia. Gastroenterology 2010;139:1497-1502.

90. Spring KJ, Zhao ZZ, Karamatic R, et al. High prevalence of sessile serrated adenomas with BRAF mutations: a prospective study of patients undergoing colonoscopy. Gastroenterology 2006;131:1400-1407.

91. Tholey DM, Shelton CE, Francis G, et al. Adenoma detection in excellent versus good bowel preparation for colonoscopy. J Clin Gastroenterol 2015;49:313-319.

92. Turner KO, Genta RM, Sonnenberg A. Lesions of all types exist in colon polyps of all sizes. Am J Gastroenterol 2018;113:303-306.

93. Wallace K, Brandt HM, Bearden JD, et al. Race and prevalence of large bowel polyps among the low-income and uninsured in South Carolina. Dig Dis Sci 2016; 61:265-272.

94. Wong S, Lidums I, Rosty C, et al. Findings in young adults at colonoscopy from a hospital service database audit. BMC Gastroenterol 2017;17(1):56.

95. Yen AW, Leung JW, Leung FW. A novel method with significant impact on adenoma detection: combined water-exchange and cap-assisted colonoscopy. Gastrointest Endosc 2013;77:944-948.

96. Rzouq F, Gupta N, Wani S, et al. Cap assisted colonoscopy for the detection of serrated polyps: a post-hoc analysis. BMC Gastroenterol 2015;15:11.

97. Bouwens MWE, Winkens B, Rondagh EJA, et al. Simple clinical risk score identifies patients with serrated polyps in routine practice. Cancer Prev Res 2013;6:855-863.

98. Lash RH, Genta RM, Schuler CM. Sessile serrated adenomas: prevalence of dysplasia and carcinoma in 2139 patients. J Clin Pathol 2010;63:681-686.

99. Pai RK, Hart J, Noffsinger AE. Sessile serrated adenomas strongly predispose to synchronous serrated polyps in non-syndromic patients. Histopathology 2010; 56:581-588.

100. Rustagi T, Rangasamy $P$, Myers M, et al. Sessile serrated adenomas in the proximal colon are likely to be flat, large and occur in smokers. World J Gastroenterol 2013;19:5271-5277.

101. Yang JF, Tang SJ, Lash RH, et al. Anatomic distribution of sessile serrated adenoma/polyp with and without cytologic dysplasia. Arch Pathol Lab Med 2015; 139:388-393.

102. Anderson JC, Weiss JE, Robinson CM, et al. Adenoma detection rates for screening colonoscopies in smokers and obese adults: data from the New Hampshire Colonoscopy Registry. J Clin Gastroenterol 2017;51(10):e95e100.

103. Butterly L, Robinson CM, Anderson JC, et al. Serrated and adenomatous polyp detection increases with longer withdrawal time: results from the New Hampshire Colonoscopy Registry. Am J Gastroenterol 2014;109:417426.

104. Clark BT, Parikh ND, Laine L. Yield of repeat forwardview examination of the right side of the colon in screening and surveillance colonoscopy. Gastrointest Endosc 2016;84:126-132.

105. ljspeert JEG, Bossuyt PM, Kuipers EJ, et al. Smoking status informs about the risk of advanced serrated polyps in a screening population. Endosc Int Open 2016; 4(1):E73-E78.

106. Vleugels JLA, ljspeert JEG, Hazewinkel Y, et al. Optical diagnosis of sessile serrated polyps: bottleneck for the optical diagnosis paradigm? J Clin Gastroenterol 2017; 51:426-432.

107. Ijspeert JEG, Tutein Nolthenius CJ, Kuipers EJ, et al. CTcolonography vs. colonoscopy for detection of high-risk sessile serrated polyps. Am J Gastroenterol 2016; 111:516-522.

108. Siegel RL, Fedewa SA, Anderson WF, et al. Colorectal cancer incidence patterns in the United States, 19742013. J Natl Cancer Inst 2017;109(8):djw322.

109. Imperiale TF, Ransohoff DF, Itzkowitz SH, et al. Multitarget stool DNA testing for colorectal-cancer screening. N Engl J Med 2014;370:1287-1297.

110. de Moor JS, Cohen RA, Shapiro JA, et al. Colorectal cancer screening in the United States: trends from 2008 to 2015 and variation by health insurance coverage. Prev Med 2018;112:199-206.

111. Zhao S, Wang S, Pan P, et al. Magnitude, risk factors, and factors associated with adenoma miss rate of tandem colonoscopy: a systematic review and metaanalysis. Gastroenterology 2019;156:1661-1674.

112. Niv Y. Changing pathological diagnosis from hyperplastic polyp to sessile serrated adenoma: systematic review and meta-analysis. Eur J Gastroenterol Hepatol 2017;29:1327-1331.

113. Jover R, Bretthauer M, Dekker E, et al. Rationale and design of the European Polyp Surveillance (EPoS) trials. Endoscopy 2016;48:571-578.

114. Holme $\varnothing$, Bretthauer M, Eide TJ, et al. Long-term risk of colorectal cancer in individuals with serrated polyps. Gut 2015;64:929-936.

115. Erichsen R, Baron JA, Hamilton-Dutoit SJ, et al. Increased risk of colorectal cancer development among patients with serrated polyps. Gastroenterology 2016; 150:895-902.

116. Cenaj O, Gibson J, Odze RD. Clinicopathologic and outcome study of sessile serrated adenomas/polyps with serrated versus intestinal dysplasia. Mod Pathol 2018;31:633-642. 
Received October 2, 2019. Accepted March 9, 2020.

\section{Correspondence}

Address correspondence to: Reinier G.S. Meester, PhD, Department of Public Health, Erasmus MC University Medical Center, PO Box 2040, 3000 CA Rotterdam, The Netherlands. e-mail: r.meester@erasmusmc.nl; fax: +3110 7038475.

\section{Acknowledgments}

We would like to acknowledge Wichor M. Bramer, PhD, at the Erasmus University Medical Library, and Christopher Stave, MLS at the Lane Medical Library at Stanford University for their advice on the literature search strategy.

g. Reinier Meester, PhD (Conceptualization: Equal; Data curation: Lead; Formal analysis: Lead; Funding acquisition: Lead; Investigation: Equal; Visualization: Lead; Writing - original draft: Lead); Marinika van Herk, MA (Data curation:
Supporting; Writing - review \& editing: Supporting); Iris Lansdorp-Vogelaar, PhD (Supervision: Supporting; Writing - review \& editing: Supporting); Ur Ladabaum, MD, MPH (Conceptualization: Equal; Funding acquisition: Supporting; Investigation: Equal; Supervision: Lead; Writing - review \& editing: Lead).

\section{Conflicts of interest}

This author discloses the following: Uri Ladabaum has acted as an advisor to UniversalDx and Lean and as a consultant to Covidence, Motus GI, Quorum, and Clinical Genomics. The remaining authors disclose no conflicts.

\section{Funding}

Supported by a Rubicon fellowship from the Netherlands Organisation for Scientific Research (to Reinier G.S. Meester) and the National Cancer Institute of the National Institutes of Health under Award Number U01 CA 199335 (to Iris Lansdorp-Vogelaar). The content of this publication is solely the responsibility of the authors and does not necessarily represent the official views of the National Institutes of Health. 


\section{Supplementary References}

1. Cheng CL, Kuo YL, Liu NJ, et al. Impact of bowe preparation with low-volume (2-liter) and intermediatevolume (3-liter) polyethylene glycol on colonoscopy quality: a prospective observational study. Digestion 2015;92:156-164.

2. Ferlay J, Soerjomataram I, Dikshit R, et al. Cancer incidence and mortality worldwide: sources, methods and major patterns in GLOBOCAN 2012. Int J Cancer 2015;136(5):E359-E386.
April 2018

2 Reviewers

2 Reviewers

2 Data collectors
4462 references

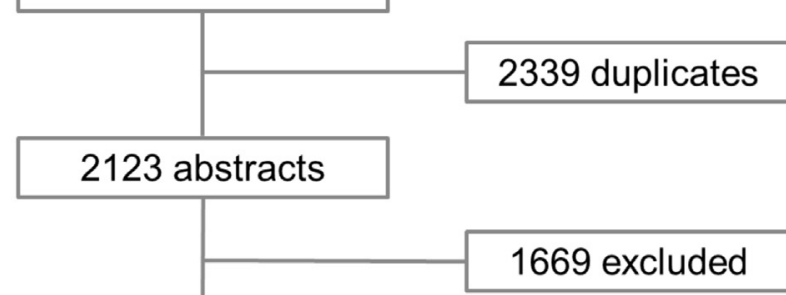

454 full texts

380 excluded 


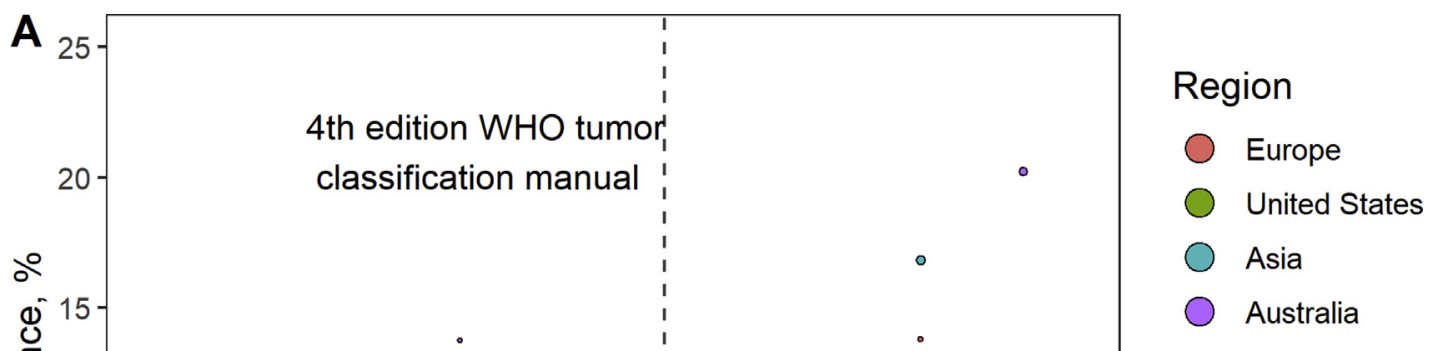

Study size
- 1,000
○ 5,000
○ 10,000
○ 25,000

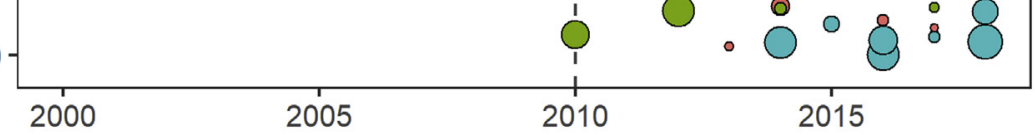

Publication year, $y$

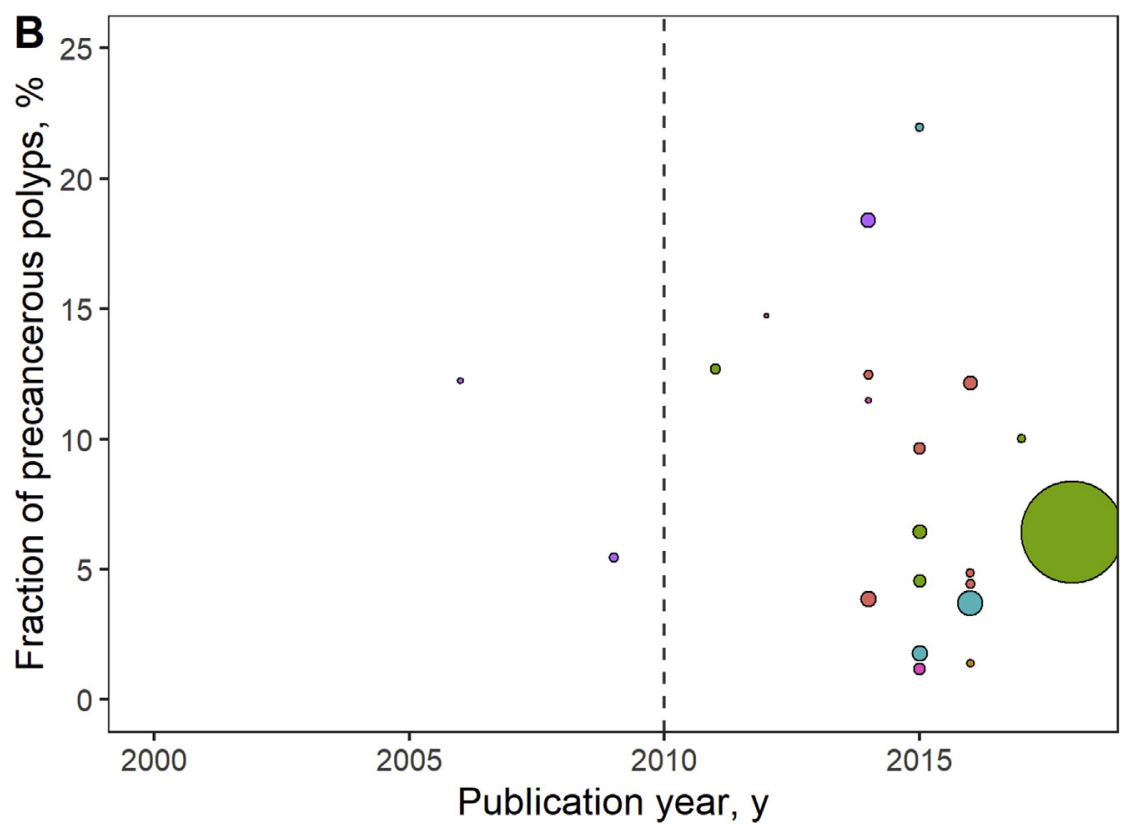

Region

Middle East

Europe

Latin America

United States

Asia

Australia

\section{Study size}

- 1,000

- 5,000

○ 10,000

○ 25,000

Supplementary Figure 2. Studies reporting SSP prevalence by year of publication. Dots indicate different studies, and size represents the population size. There was no significant overall trend over time in reported prevalence in $(A)$ (excluding the 2006 outlier, $+0.1 \% \mathrm{p} / \mathrm{y} ; 95 \% \mathrm{Cl},-0.2$ to $0.4 ; P=.49)$ or $(B)(-0.3 \% \mathrm{p} / \mathrm{y} ; 95 \% \mathrm{Cl},-1.1$ to $0.5 ; P=.46)$. (A) Prevalence trends differed by region: Europe, $+0.1 \% / y(95 \% \mathrm{Cl},-0.9$ to $1.0 ; P=.87),+0.3 \% / \mathrm{y}(95 \% \mathrm{Cl}, 0.0-0.7 ; P=.03) ;$ Asia, $+0.1 \% / \mathrm{y}(95 \%$ $\mathrm{Cl},-0.7$ to $0.9 \% ; P=.83)$; and Australia, $+0.8 \% / \mathrm{y}(95 \% \mathrm{Cl},-43.9$ to $45.6 ;>2006, P=.85)$. 

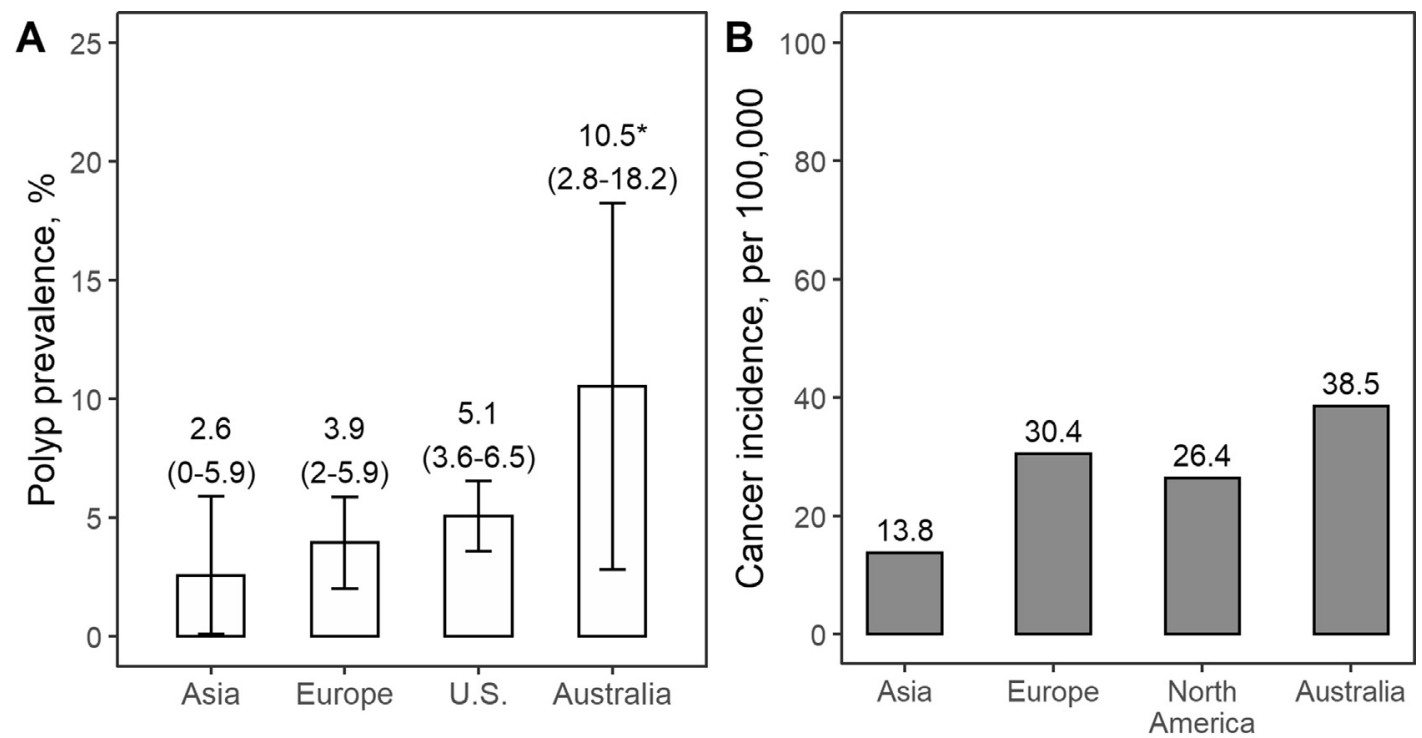

\begin{tabular}{|lcccc|}
\hline Studies & 9 & 11 & 16 & 4 \\
Subjects & 142877 & 56291 & 108240 & 3475 \\
\hline
\end{tabular}

Supplementary Figure 3. SSP $(A)$ prevalence and $(B)$ cancer incidence by world region. Bars in $A$ represent pooled mean estimates across studies from random-effects meta-regression (see Supplementary Figure 4 for corresponding forest plots), whiskers represent $95 \% \mathrm{Cls}$, and asterisks mark statistically significant differences compared to studies from the United States at a $5 \%$ significance threshold. Excluding 1 statistical outlier, ${ }^{\mathrm{S}}$ the mean prevalence for Asia was $0.9 \%(95 \% \mathrm{Cl}, 0.4-1.3)$, also significantly different from the US prevalence $(P=.004)$. Incidence data were taken from Ferlay et al. ${ }^{\mathrm{S} 2}$ No incidence data specific to the United States were available from this publication, so North American data excluding Central America are presented instead. 
A

Aniwan, 2017; n=1713

Cao, 2016; $n=28981$

Chen, 2016; $n=22318$

Cheng, 2015; $n=814$

Kim, 2014; $n=28544$

$\mathrm{Ng}, 2015 ; n=4989$

Okhi, 2018; $n=3691$

Pyo, 2018; $n=35126$

Sano, 2018; $n=16701$

Mean $(95 \% \mathrm{Cl})$

B
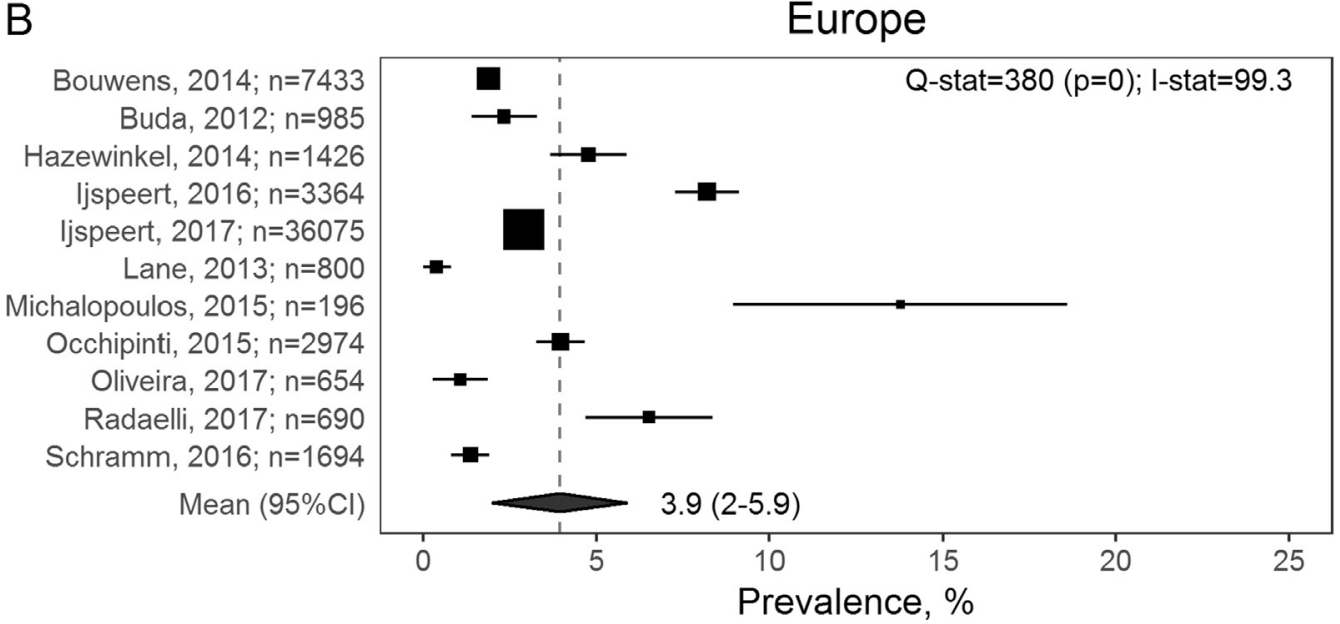

Asia

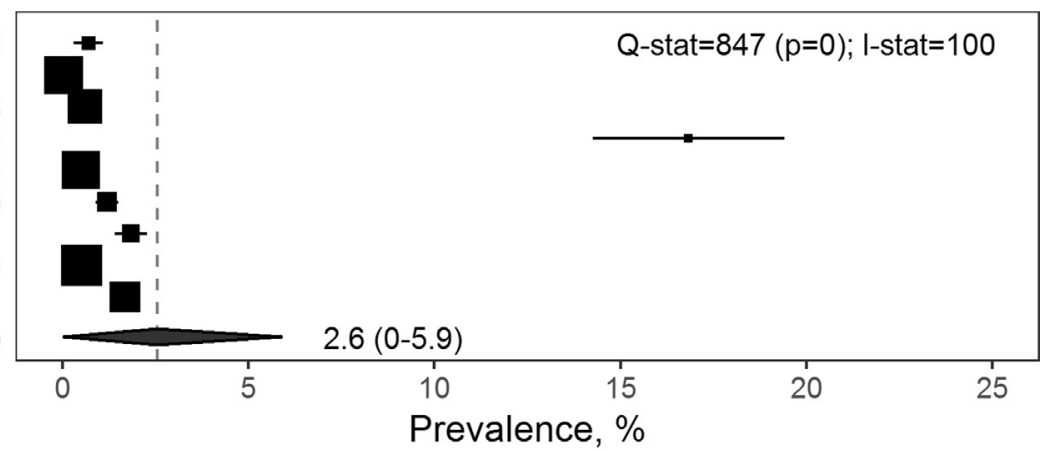

Supplementary Figure 4. Forest plots of SSP prevalence by world region: $(A)$ Asia, $(B)$ Europe, $(C)$ the United States, and $(D)$ Australia. Dots represent study means, symbol size represents population size, whiskers represent $95 \%$ Cls, and the polygon represents the pooled mean estimated from random-effects metaregression. In $A$, For Cao, $2016\left(\right.$ Cao et al ${ }^{40}$ ), the number of SSPs was used as a proxy for the prevalence numerator. The total prevalence of serrated polyps including hyperplastic polyps in that study was $0.5 \%$. Excluding 1 extreme statistical outlier, ${ }^{\mathrm{S} 1}$ the mean prevalence for Asia was $0.9 \%(95 \% \mathrm{Cl}, 0.5-1.3)$. 


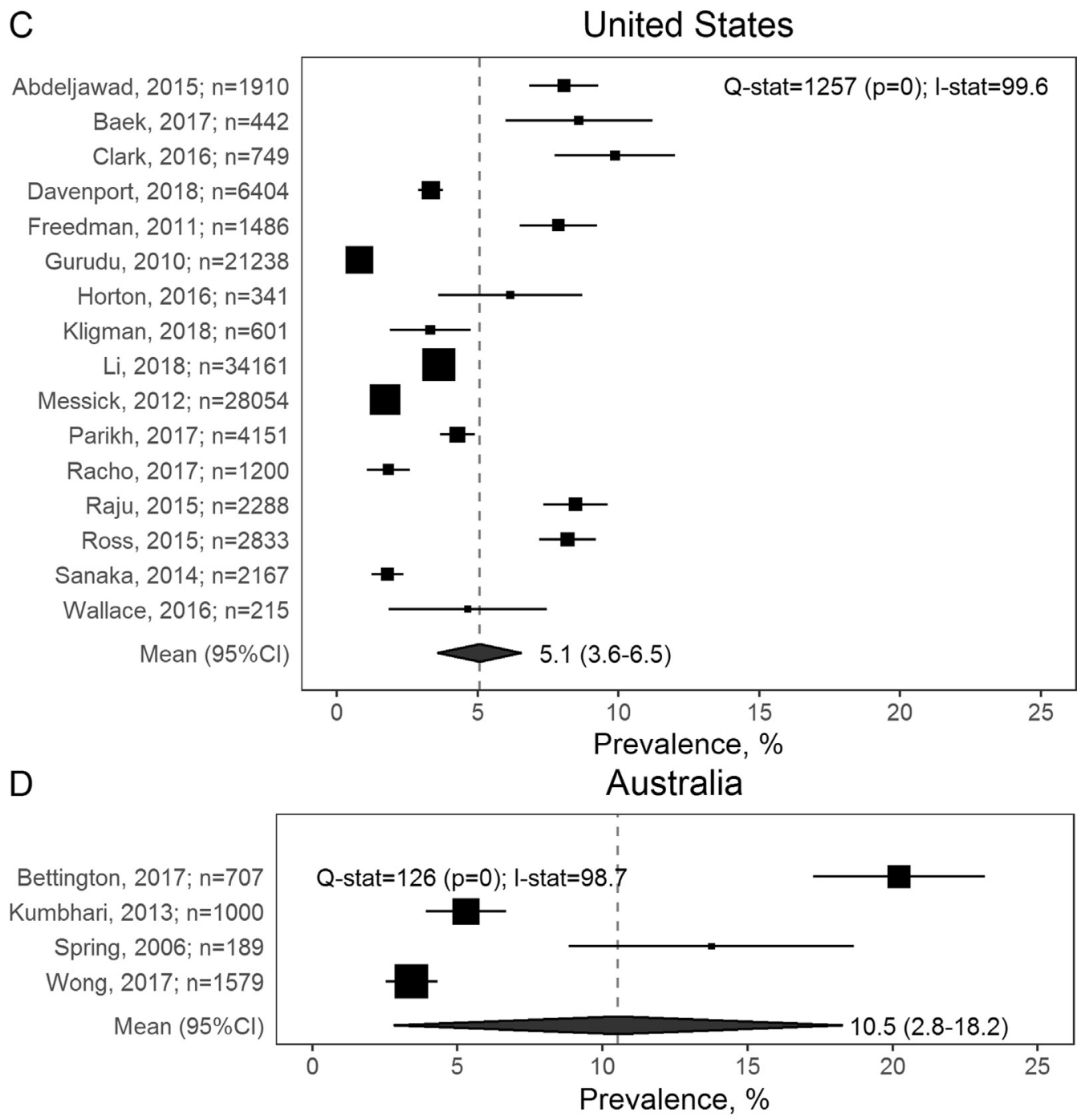

Supplementary Figure 4. (continued). 
A

Large hyperplastic polyps

Alvarez, 2013; n=5059

Hazewinkel, 2014; n=1426

ljspeert, 2017; n=242024

Kahi, 2015; n=1910

Lieberman, 2008; n=13992

Occhipinti, 2015; n=2974

Rzouq, 2015; $n=420$

Wallace, 2016; n=215

Mean $(95 \% \mathrm{Cl})$

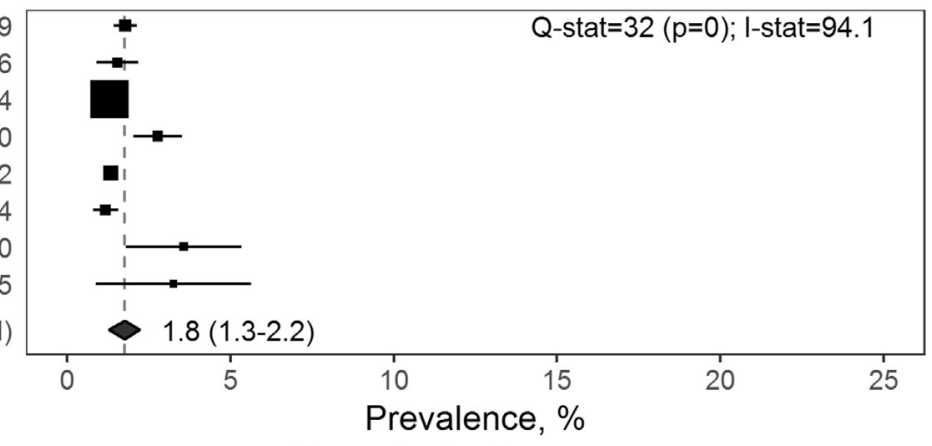

B

Serrated adenoma

Adike, 2018; $\mathrm{n}=1991$

Alvarez, 2013; n=5059

Fantry, 2016; n=657

Glazer, 2008; n=17226

Gourevitch, 2018; n=85526

Hassan, 2017; n=658

Hetzel, 2010; n=7192

Imler, 2015; $n=42569$

Lieberman, 2008; n=13992

Pezzoli, 2007; n=562

Pohl, 2011; n=1008

Raju, 2013; n=343

Rodriguez, 2016; n=155

Rodriguez, 2016; n=60

Rzouq, 2015; $n=420$

Mean $(95 \% \mathrm{Cl})$

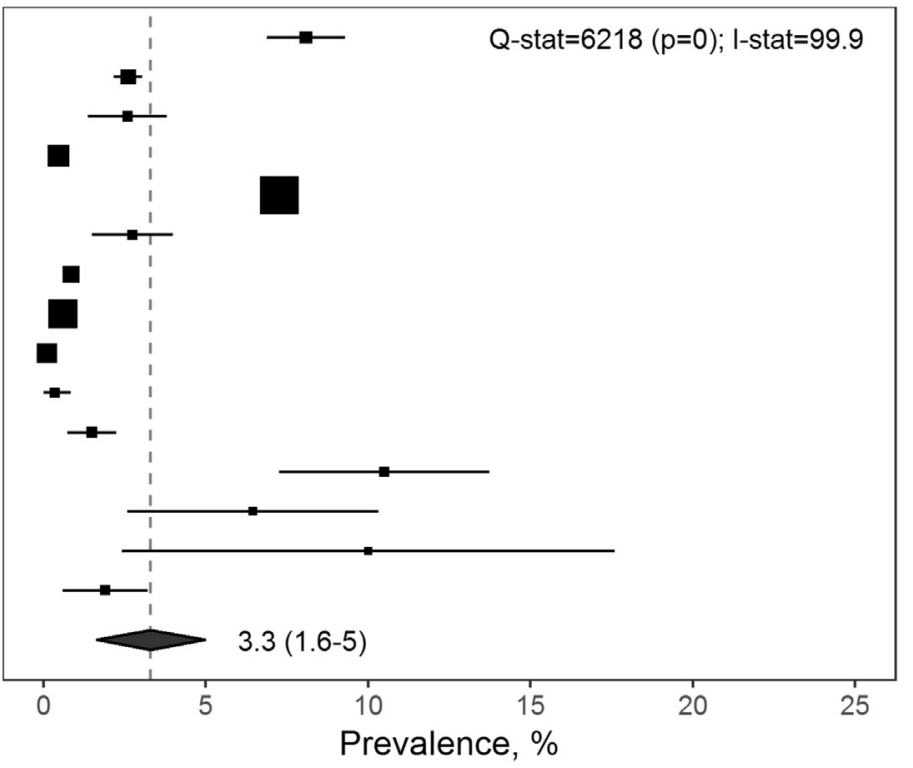

C

Proximal serrated polyps

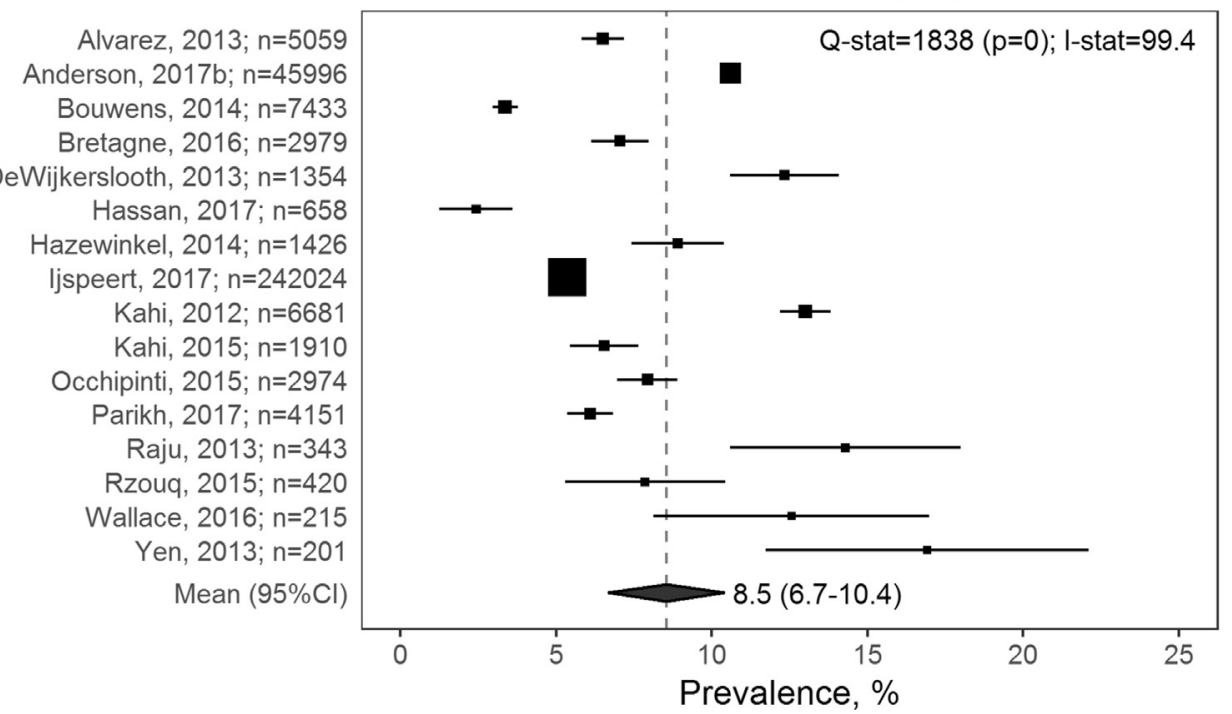


Supplementary Figure 5. Forest plots of SSP prevalence by clinical definition: $(A)$ large hyperplastic polyps, $(B)$ serrated adenomas, $(C)$ proximal serrated polyps, $(D)$ SSPs, $(E)$ SSPs or traditional serrated adenomas, $(F)$ clinically relevant size or histology, and $(G)$ clinically relevant location or histology. Dots represent study means, symbol size represents population size, whiskers represent $95 \% \mathrm{Cls}$, and the polygon represents the pooled mean estimated from random-effects meta-regression. Large indicates $>10-\mathrm{mm}$ diameter. Proximal means left of the splenic flexure. In C, Kahi, 2012 (Kahi et al ${ }^{59}$ ) partly overlaps with the $2015^{60}$ study but used wider selection criteria, justifying independent inclusion here. In $D$, the prevalence of SSPs in studies reporting both SSPs and traditional serrated polyps was 4.1\% (95\% Cl, 2.6-5.5). Outcomes in $F$ and $G$ were composite definitions consisting of clinically relevant histology (sessile serrated or traditional serrated), size (large), and location (proximal). In F, Anderson, 2017b (Anderson et $\mathrm{al}^{33}$ ) reported the combined prevalence of SSPs, traditional serrated adenoma, distal hyperplastic polyps $>10 \mathrm{~mm}$, and proximal hyperplastic polyps $>5 \mathrm{~mm}$ in diameter. Payne, $2014\left(\mathrm{Payne}^{\mathrm{et}} \mathrm{al}^{74}\right.$ ) combined prevalence of SSPs or proximal hyperplastic polyps $>10 \mathrm{~mm}$. Riverso, 2017 (Riverso et al ${ }^{82}$ ) combined SSPs, traditional serrated adenoma, and proximal hyperplastic polyps $>10 \mathrm{~mm}$. Schreiner, 2010 (Schreiner et al ${ }^{89}$ ) combined SSPs, traditional serrated adenoma, or hyperplastic polyps $>10 \mathrm{~mm}$. For other studies, this outcome was derived by adding up the prevalence of SSPs, traditional serrated adenoma, and large hyperplastic polyps. In G, Anderson, 2013 (Anderson et al ${ }^{31}$ ) and Raju, 2013 (Raju et $\mathrm{al}^{81}$ ) combined prevalence of SSPs, traditional serrated adenomas, and proximal hyperplastic polyps. Anderson, 2017a (Anderson et $\mathrm{al}^{32}$ ) and Rzouq, 2015 (Rzouq et $\mathrm{al}^{96}$ ) combined SSPs, traditional serrated adenoma, proximal hyperplastic polyps, and distal hyperplastic polyps $>10 \mathrm{~mm}$. Racho, 2017 (Racho et $\mathrm{al}^{78}$ ) combined SSPs, traditional serrated adenoma, proximal hyperplastic polyps, and distal hyperplastic polyps $>5 \mathrm{~mm}$. For other studies, this outcome was derived by adding up prevalence of SSPs, traditional serrated adenoma, proximal, and >10-mm hyperplastic polyps. 
D

Abdeljawad, 2015; $n=1910$ Baek, 2017; $n=442$

Bouwens, 2014; $n=7433$

Buda, 2012; $n=985$

Clark, 2016; $n=749$

Davenport, 2018; $n=6404$

Freedman, 2011; $n=1486$

Gurudu, 2010; $n=21238$

Hazewinkel, 2014; n=1426

Horton, 2016; $n=341$

ljspeert, 2016; $n=3364$

ljspeert, 2017; n=36075

Kligman, 2018; $n=601$ Lane, 2013; $n=800$

Li, 2018; $n=34161$

Messick, 2012; $\mathrm{n}=28054$

Michalopoulos, 2015; $n=196$

Occhipinti, 2015; n=2974

Oliveira, 2017; $n=654$

Parikh, 2017; $n=4151$

Racho, 2017; n=1200

Radaelli, 2017; n=690

Raju, 2015; $n=2288$

Ross, 2015; $n=2833$

Sanaka, 2014; $n=2167$

Schramm, 2016; $n=1694$

Wallace, 2016; $n=215$

Mean $(95 \% \mathrm{Cl})$

E
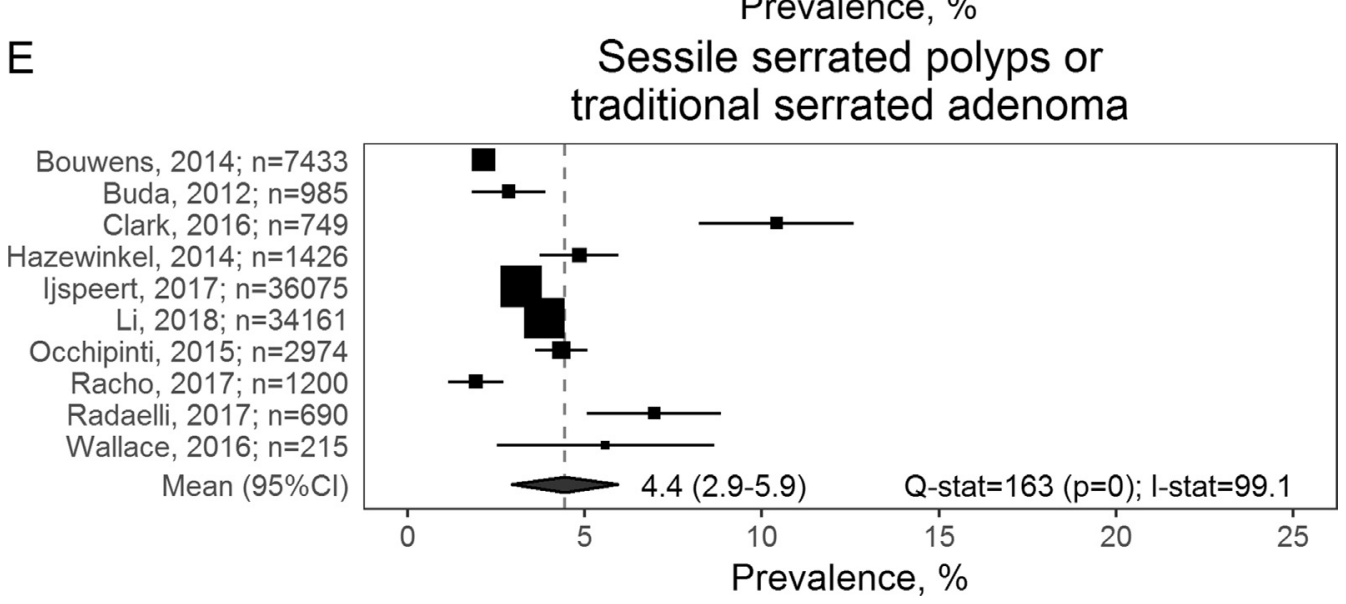

Supplementary Figure 5. (continued).

Sessile serrated polyps

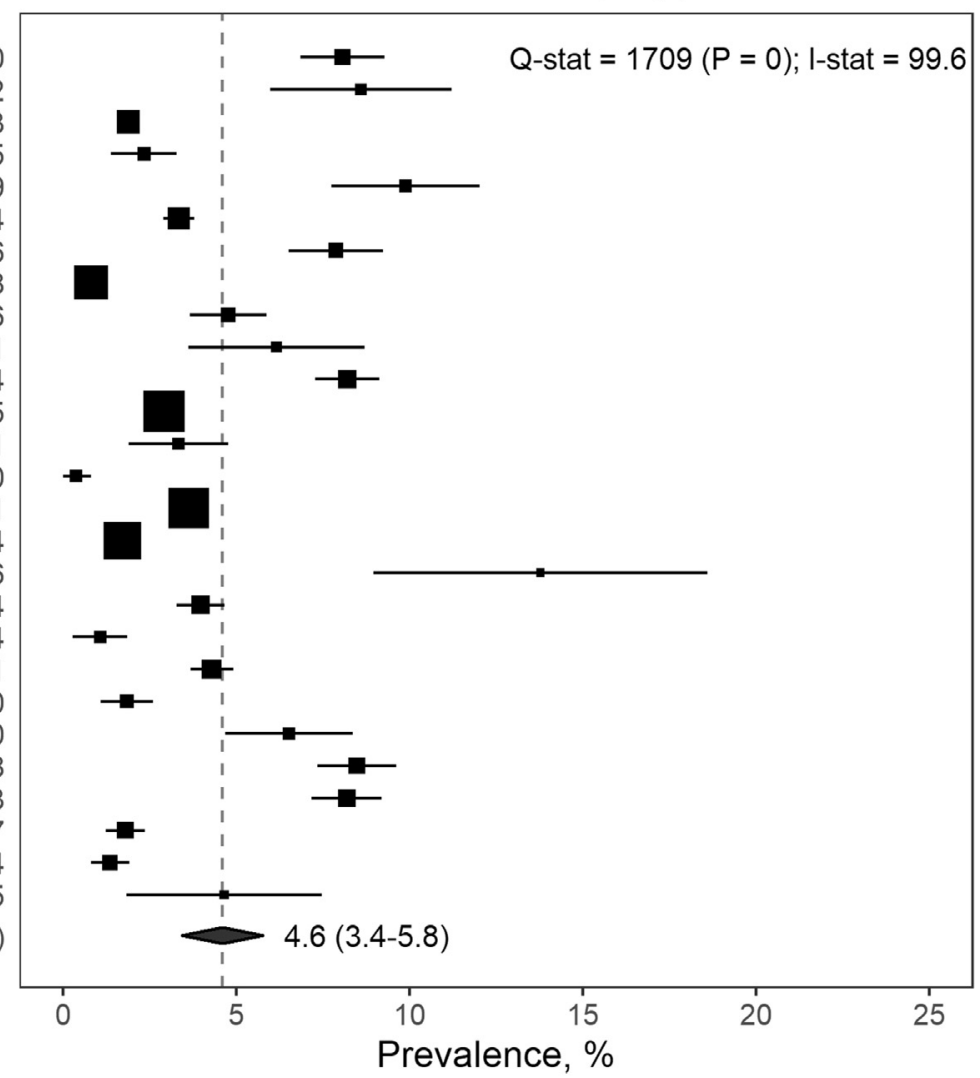

Sessile serrated polyps or

traditional serrated adenoma

Bus, $2014 ; n=7433$

Buda, 2012; $n=985$

Clark, 2016; $n=749$

zewinkel, 2014; $n=1426$

(1)

chipinti, 2015; $n=2974$

Racho, 2017; $n=1200$

Radaelli, 2017; $n=690$

Wallace, 2016; n=215

Mean $(95 \% \mathrm{Cl})$ 
F

Anderson, 2017b; n=45996

Hazewinkel, 2014; n=1426

ljspeert, 2017; n=36075

Occhipinti, 2015; n=2974

Payne, 2014; $n=7215$

Riverso, 2017; n=2083

Rzouq, 2015; $n=420$

Schreiner, 2010; $n=3121$

Wallace, 2016; $n=215$

Mean $(95 \% \mathrm{Cl})$

G

Anderson, 2013; $n=9100$ Anderson, 2017a; $n=1383$

Bouwens, 2014; $n=7433$

Hassan, 2017; $n=658$ Hazewinkel, 2014; n=1426

ljspeert, 2017; $n=36075$

Kahi, 2015; $n=1910$ Occhipinti, 2015; n=2974

Racho, 2017; n=1200

Raju, 2013; n=343

Rzouq, 2015; $n=420$

Wallace, 2016; $n=215$

Mean $(95 \% \mathrm{Cl})$
"Clinically-relevant" size or histology

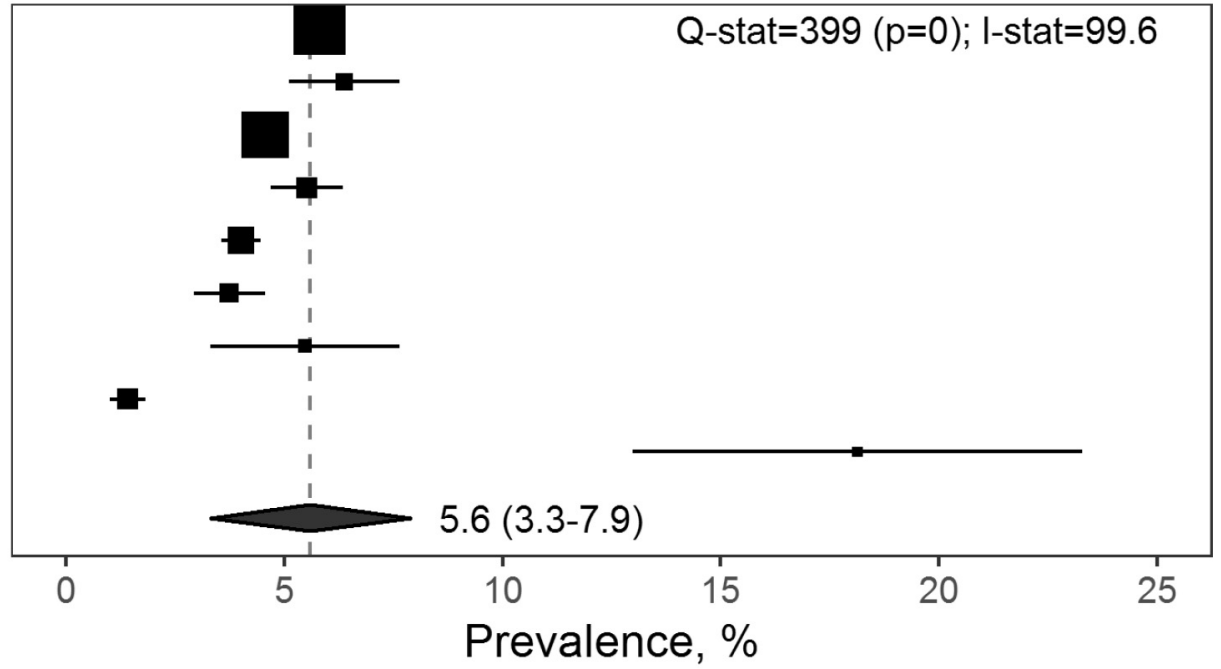

"Clinically-relevant" location or histology

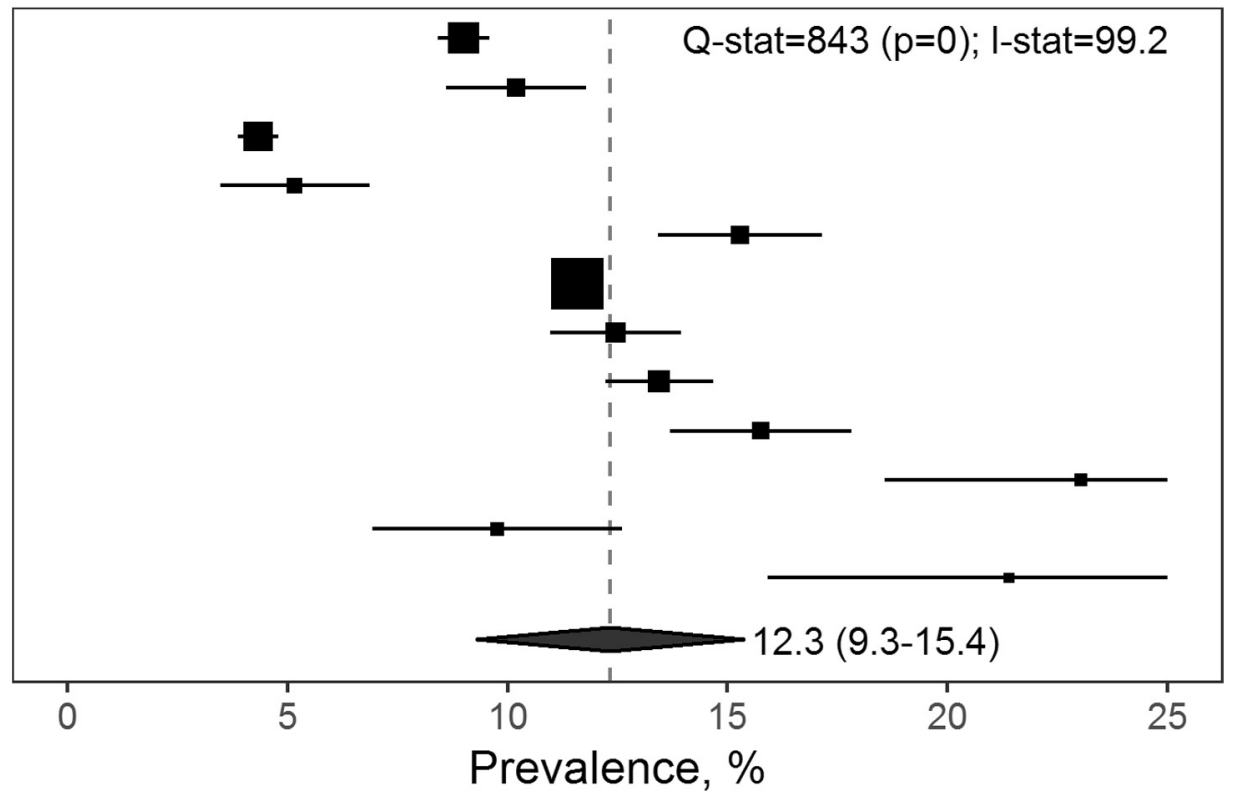

Supplementary Figure 5. (continued). 
A

Any exam indication

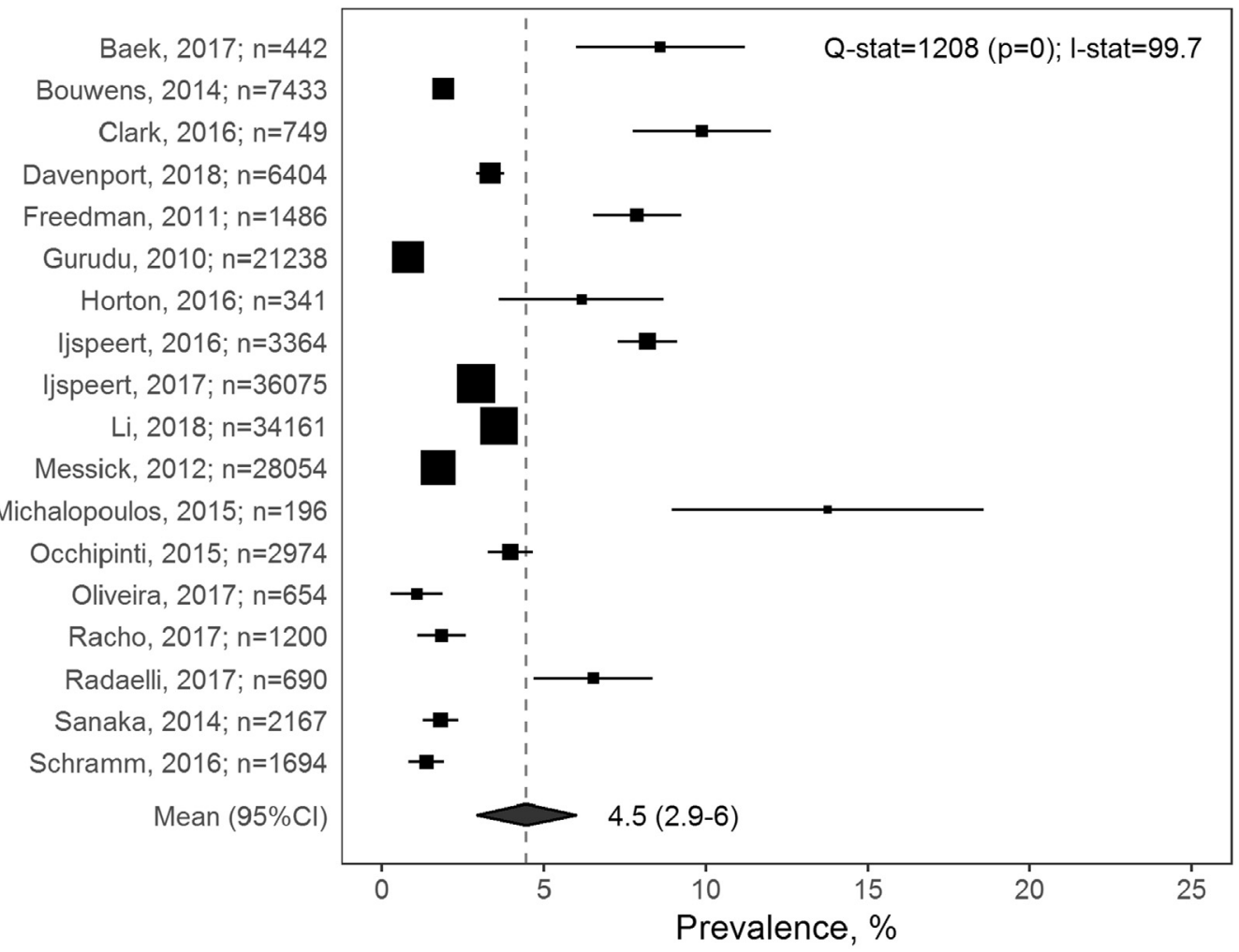

B

Any screening exam

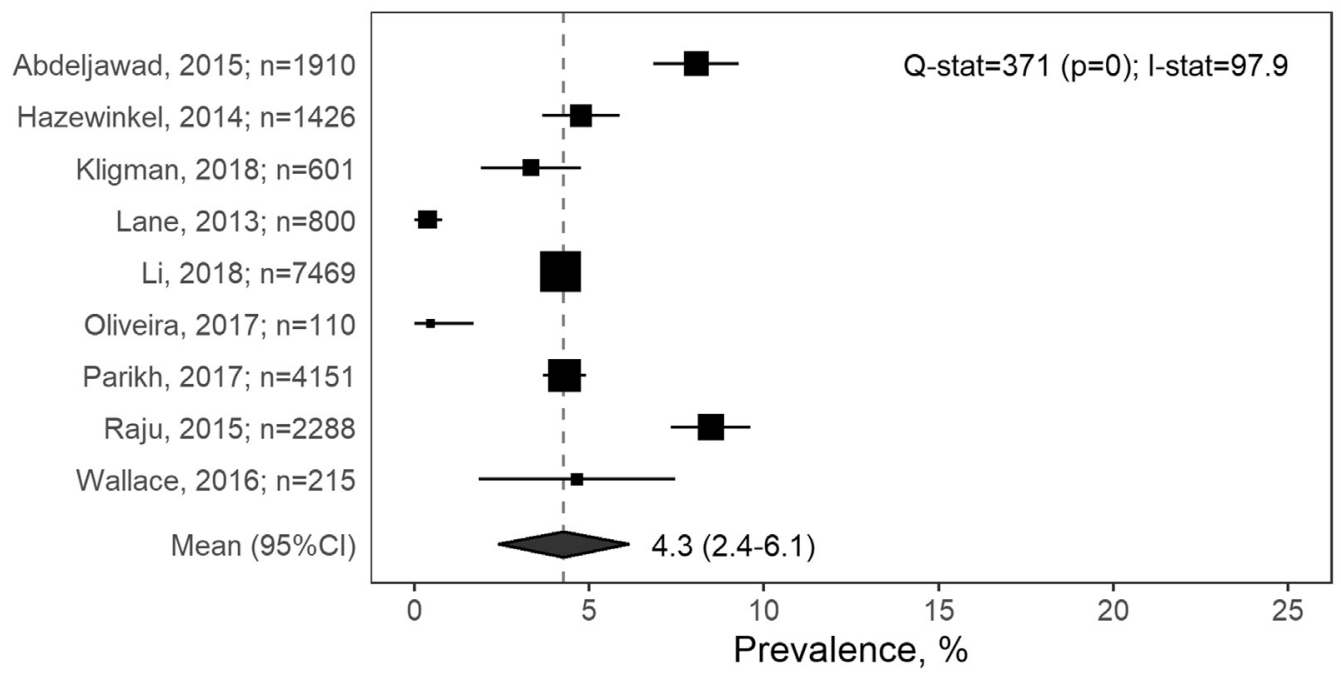

C

First screening exam

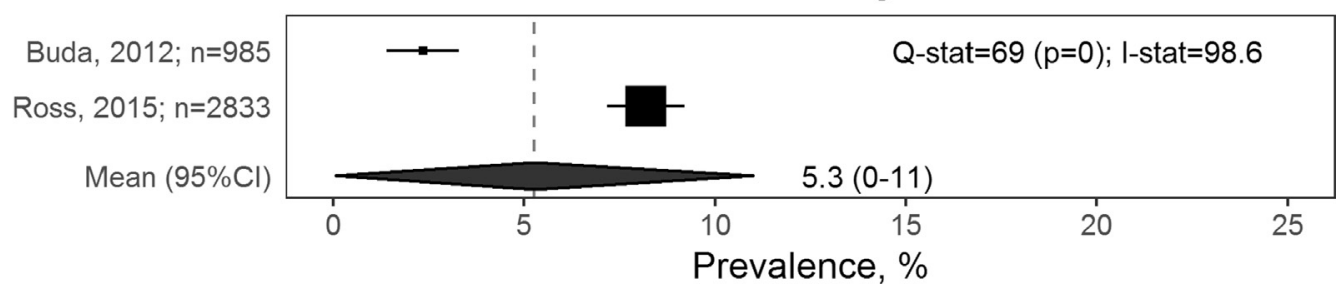


Supplementary Figure 6. Forest plots of SSP prevalence by examination indication and quality level. Dots represent study means, symbol size represents population size, whiskers represent $95 \% \mathrm{Cls}$, and the polygon represents the pooled mean estimated from random-effects metaregression. Good-excellent bowel preparation means good-excellent by Aronchick scale, 7-9 Boston Bowel Preparation Score, or preparation according to split-dose regimens. High-quality examination indicates that it was performed with enhanced endoscopes (eg, cap-assisted) or by providers from the upper quartile (minimum) of SSP detection rates. More detail is underneath the panels. In E, Clark, 2016 (Clark and Laine ${ }^{43}$ ) selected examinations with 7-9 Boston Bowel Preparation Score. Horton, 2016 (Horton et al $^{54}$ ) and Radaelli, 2017 (Radaelli et al $^{79}$ ) selected examination with split-dose bowel preparation. Sanaka, 2014 (Sanaka et $\mathrm{al}^{86}$ ) selected good-excellent preparation by Aronchick scale. In $F$, data for the highest detectors were extracted from ljspeert, 2015 (ljspeert et al ${ }^{55}$ ) (upper quartile of relevant serrate polyp detection rates); Li, $2017^{65}$ (upper quintile of SSP detection rates); and Racho, 2017 (Racho et al ${ }^{78}$ ) (highest 4/15 SSP detection rates). From Baek, 2017 (Baek et $\mathrm{al}^{35}$ ), data for endocuff-assisted colonoscopy were extracted. 
D

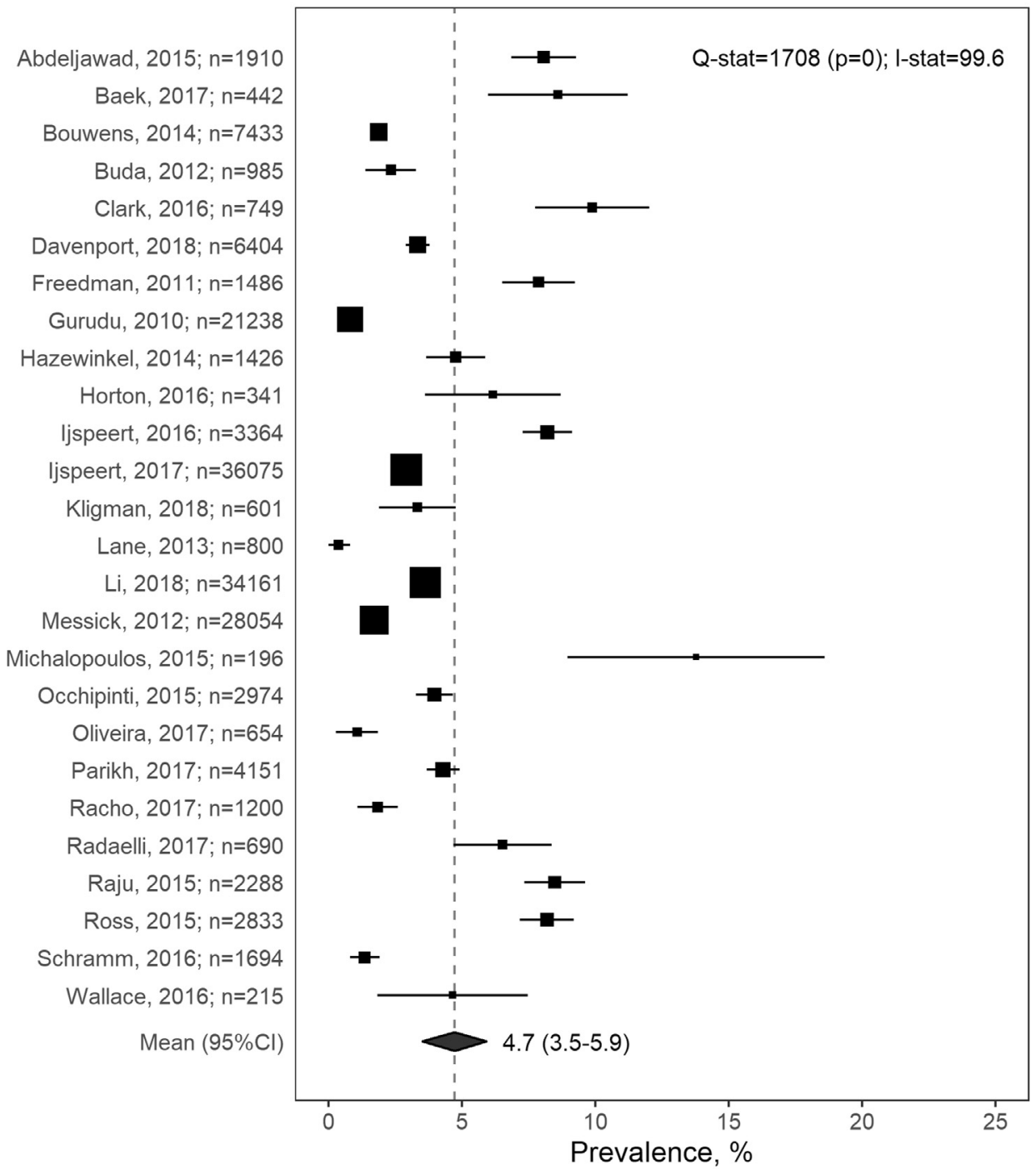

E

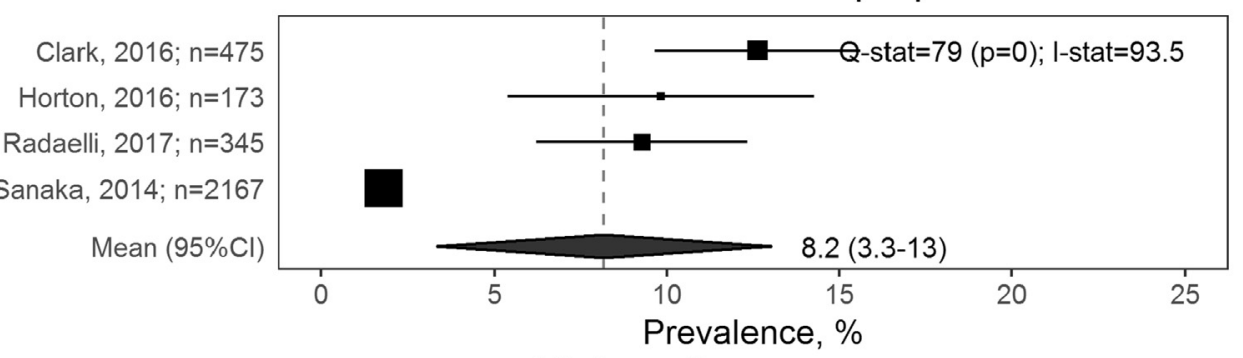

F

High performance exam

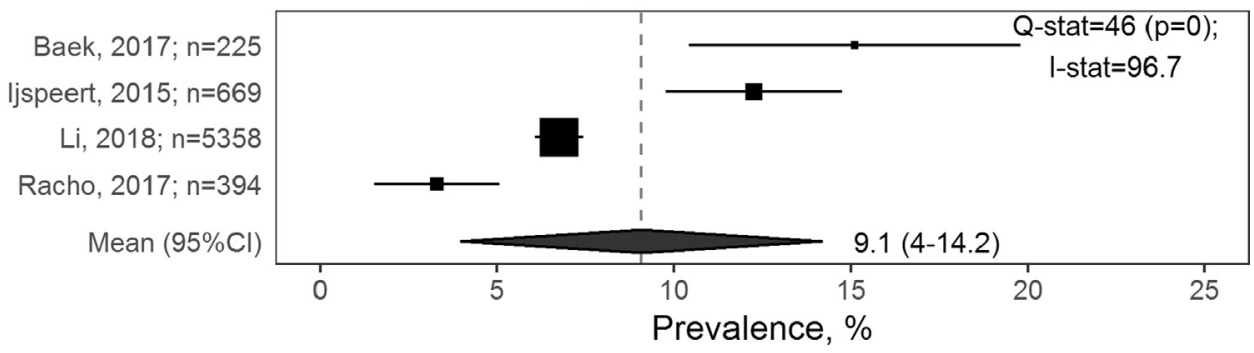

Supplementary

Figure 6. (continued). 


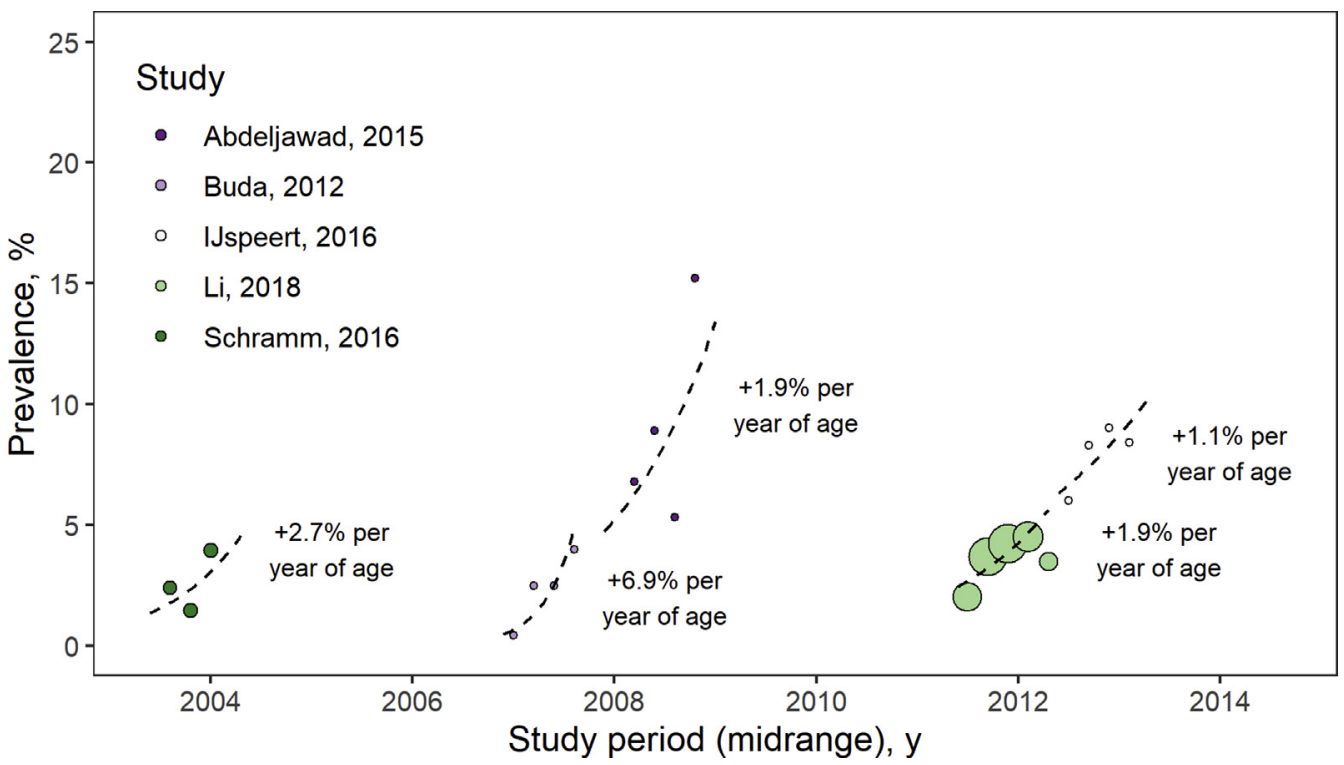

Supplementary Figure 7. Prevalence of SSPs by age and study period. This plot shows the studies reporting prevalence by age in Figure 5 by study period (midrange). Denominators were unknown for Abdeljawad, 2015 (Abdeljawad et al ${ }^{28}$ ); Buda, 2012 (Buda et $\mathrm{al}^{39}$ ); and ljspeert, 2016 (ljspeert et $\mathrm{al}^{56}$ ) and fixed at $\mathrm{n}=100$ for this figure. Different markers of a similar color represent the age-specific results within each study. Age groups were horizontally spread around the study period's midrange years to show the age pattern (from left to right: youngest to oldest), not to convey differences in timing of observations between individual age groups. Number indicates the relative increase in prevalence by age year.

\section{Supplementary}

Figure 8. Prevalence of $(A)$ SSPs vs $(B)$ adenomatous polyps by sex. Bars represent pooled mean estimates across studies from random-effects metaregression (see Supplementary Figure 8 for corresponding forest plots). Whiskers represent 95\% Cls.
A

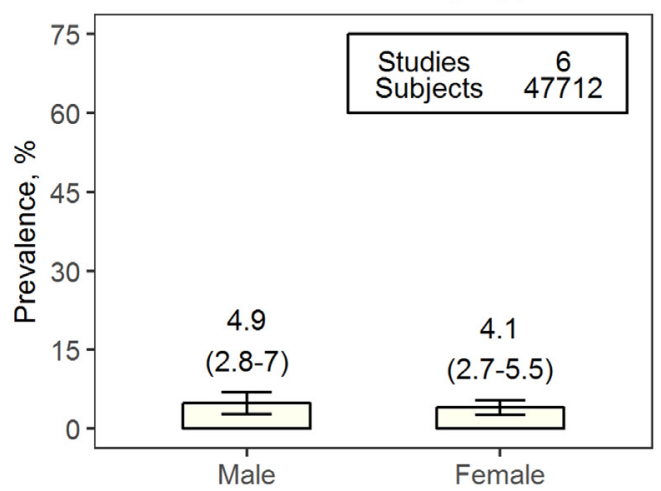

B Adenomatous polyps

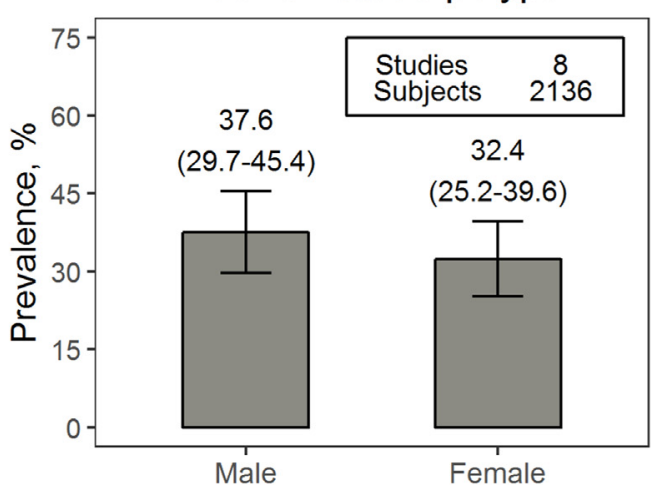




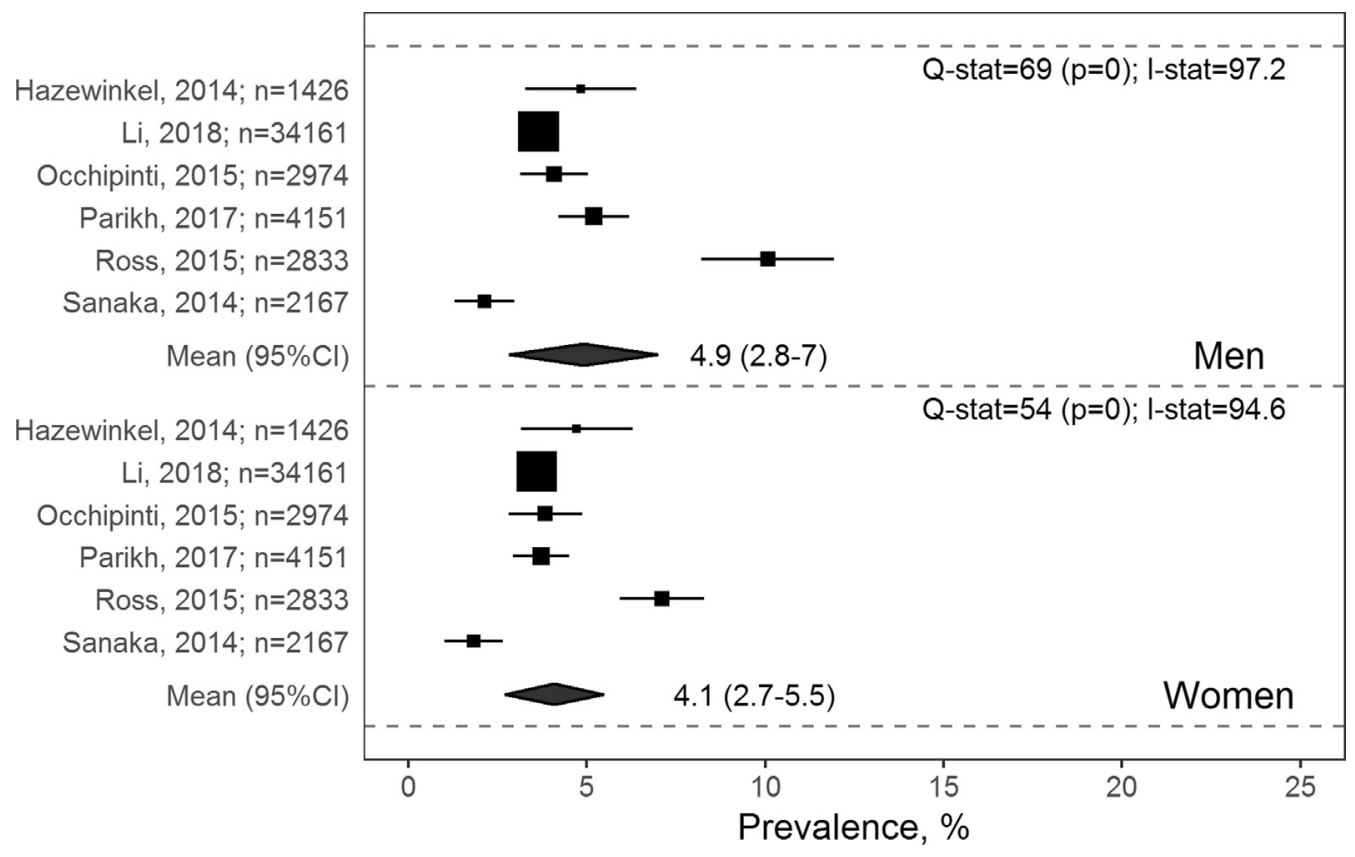

Supplementary Figure 9. Forest plot of SSP prevalence by sex. Dots represent study means, symbol size represents population size, whiskers represent $95 \%$ Cls, and the polygon represents the pooled mean estimated from random-effects metaregression.

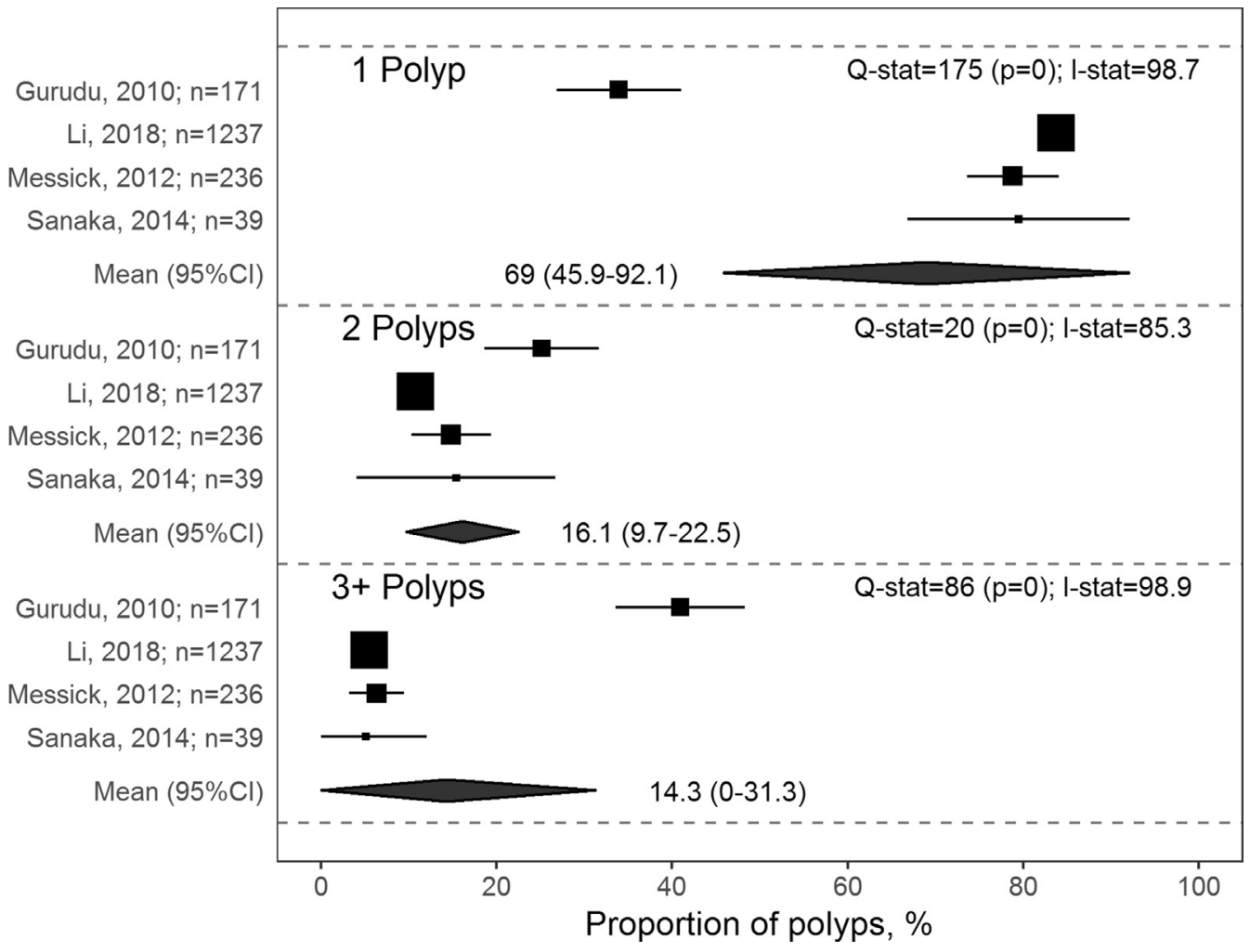

Supplementary Figure 10. Forest plot of the multiplicity distribution of SSPs. Dots represent study means, symbol size represents population size, whiskers represent $95 \% \mathrm{Cls}$, and the polygon represents the pooled mean estimated from random-effects metaregression. 


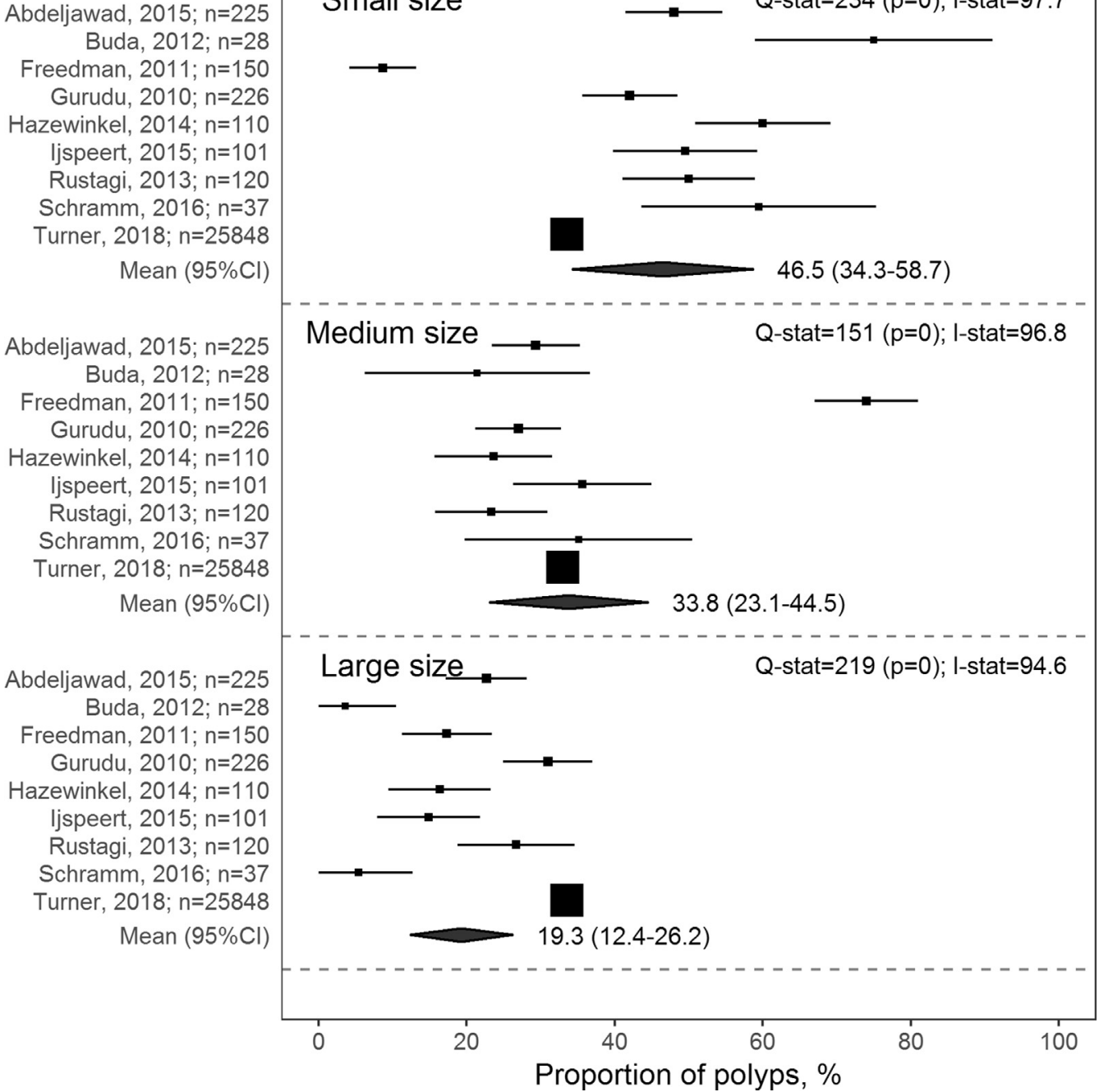

Supplementary Figure 11. Forest plot of the size distribution of SSPs. Dots represent study means, size represents study population size, whiskers represent $95 \% \mathrm{Cls}$, and polygons represent pooled mean estimates from random-effects metaregression. Size was divided into small $(0-5 \mathrm{~mm})$, medium $(6-9 \mathrm{~mm})$, and large $(10+\mathrm{mm})$. 


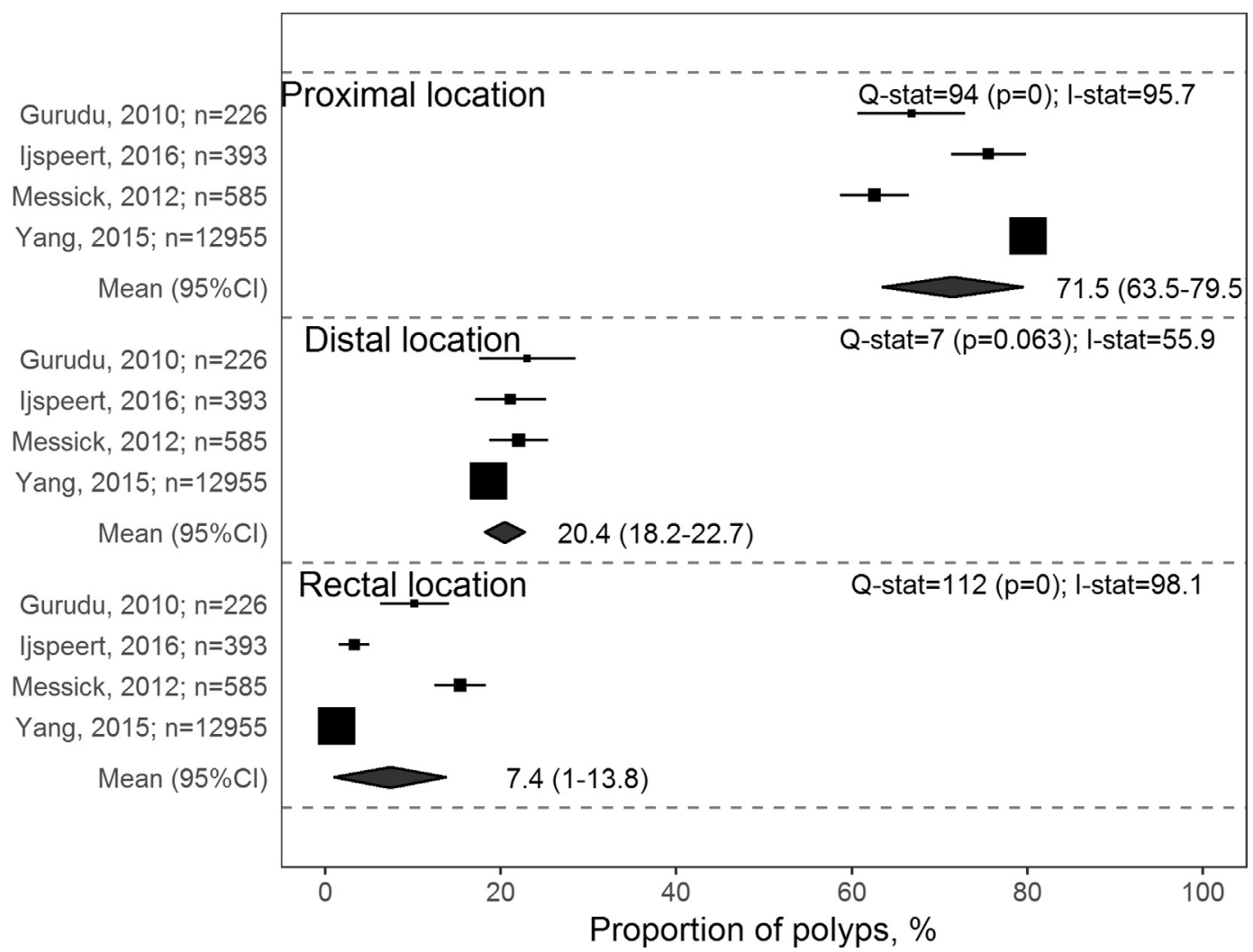

Supplementary Figure 12. Forest plot of the location distribution of SSPs. Dots represent study means, size represents study population size, whiskers represent $95 \% \mathrm{Cls}$, and polygons represent pooled mean estimates from random-effects metaregression. Location was divided into proximal (cecum, ascending colon, hepatic flexure, transverse colon), distal (splenic flexure, descending colon, sigmoid colon), and rectal (rectum).

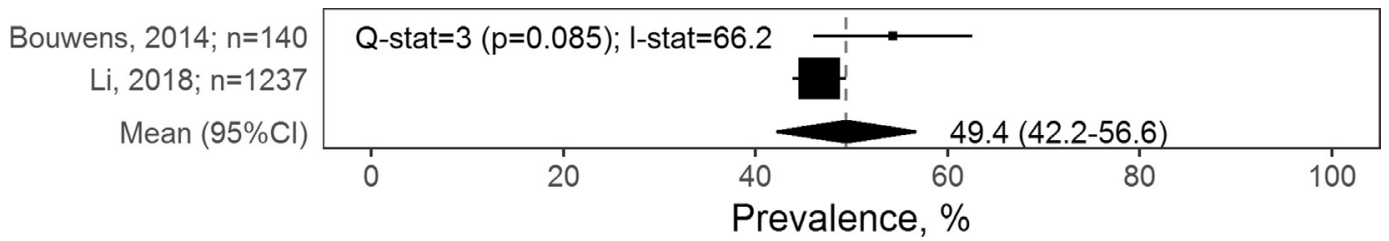

Supplementary Figure 13. Proportion of patients with SSPs with synchronous adenoma. Dots represent study means, size represents study population size, whiskers represent $95 \% \mathrm{Cls}$, and polygons represent pooled mean estimates from randomeffects metaregression. 


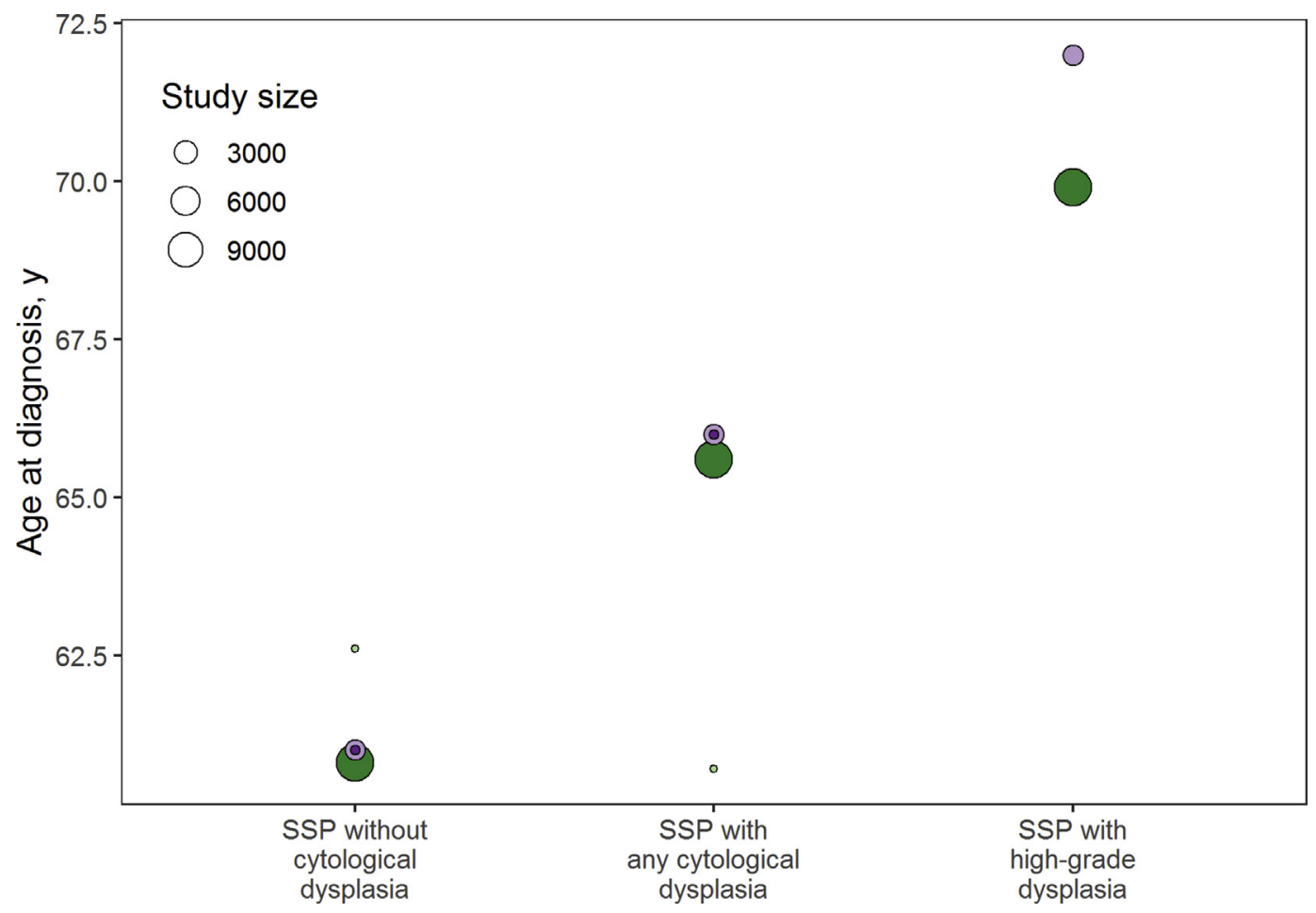

Supplementary Figure 14. Age at detection of SSPs with/without cytologic dysplasia. Dots represent study means, colors represent different studies, and size represents relative population size. 
Supplementary Table 1.Study Selection Criteria (PICOS)

\begin{tabular}{|c|c|c|c|c|c|}
\hline Research question & Population & Intervention & Comparison & Outcome & Study design \\
\hline 1. Prevalence & $\begin{array}{l}\text { US general } \\
\text { population or } \\
\text { similar }\end{array}$ & $\begin{array}{l}\text { Autopsy, } \\
\text { colonoscopy }\end{array}$ & - & SSP prevalence ${ }^{a}$ & Cross-sectional \\
\hline \multicolumn{6}{|l|}{ a. By calendar year } \\
\hline b. By world region & & & $\begin{array}{l}\text { vs other world regions, and } \\
\text { CRC incidence }\end{array}$ & & \\
\hline d. By age, sex ${ }^{C}$ & & & vs adenoma & & \\
\hline $\begin{array}{l}\text { e. By examination } \\
\text { indication }^{d}\end{array}$ & & & $\begin{array}{l}\text { unselected vs screening } \\
\text { examinations }\end{array}$ & & \\
\hline $\begin{array}{l}\text { f. By examination } \\
\text { quality }^{e}\end{array}$ & & & $\begin{array}{l}\text { unselected vs high-quality } \\
\text { examinations }\end{array}$ & & \\
\hline \multirow{4}{*}{$\begin{array}{l}\text { 2. Clinical features } \\
\text { a. Number }\end{array}$} & SSP patients & Colonoscopy & & $\%$ of SSPs (/patients) $)^{f}$ & \\
\hline & & & vs adenoma & 1 & \\
\hline & & & & 2 & \\
\hline & & & & $3+$ & \\
\hline \multirow[t]{3}{*}{ b. Size } & & & vs adenoma & $1-5 \mathrm{~mm}$ & \\
\hline & & & & $6-9 \mathrm{~mm}$ & \\
\hline & & & & $10+\mathrm{mm}$ & \\
\hline \multirow[t]{3}{*}{ c. Anatomic location } & & & vs adenoma & Proximal & \\
\hline & & & & Distal & \\
\hline & & & & Rectal & \\
\hline
\end{tabular}

PICOS, population, intervention, comparison, outcome, study design.

${ }^{a}$ Among patients and precancerous polyps. Including traditional serrated adenoma, if not distinguished. Following study criteria for diagnosis, considering SSPS and serrated adenoma as interchangeable terms.

${ }^{b}$ Including studies without reported SSP prevalence.

${ }^{c}$ Autopsy studies.

dUnselected examinations vs examinations for screening or initial screening.

eUnselected examinations vs examinations with high polyp detectors or enhanced endoscopes.

${ }^{f}$ For $2 \mathrm{a}$ and $2 \mathrm{~d}$, the denominator is the number of SSP patients. 
Supplementary Table 2. Literature Search

\begin{tabular}{|c|c|c|}
\hline Database & Search term & Number of records \\
\hline Ovid MEDLINE & 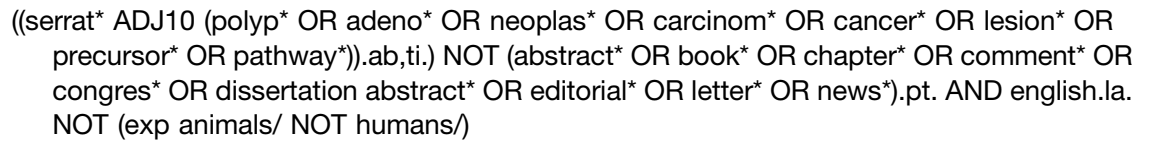 & 1343 \\
\hline Embase & $\begin{array}{l}\text { ('serrated polyp'/de OR (serrat* NEAR/10 (polyp* OR adenom* OR neoplas* OR lesion* OR } \\
\text { precursor* OR pathway*)):ab,ti) NOT ([Conference Abstract]/lim OR [Letter]/lim OR [Note]/ } \\
\lim \text { OR [Editorial]/lim) AND [English]/lim NOT ([animals]/lim NOT [humans]/lim) }\end{array}$ & 1353 \\
\hline Web of Science & 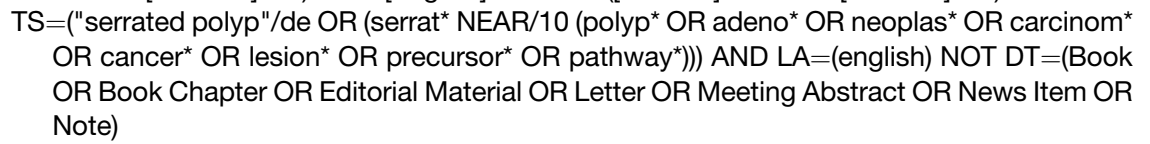 & 1654 \\
\hline Cochrane Library & $\begin{array}{l}\text { ((serrat* }{ }^{\star} \text { NEAR/10 }\left(\text { polyp }^{\star} \text { OR adeno* OR neoplas }{ }^{\star} \text { OR carcinom* }{ }^{\star} \text { OR cancer }{ }^{\star} \text { OR lesion* OR }\right. \\
\left.\text { precursor }^{\star} \text { OR pathway }\right) \text { ):ab,ti) }\end{array}$ & 112 \\
\hline
\end{tabular}




\section{External validity}

1. Was the study's target population a close representation of the national population in relation to relevant variables, e.g. age, sex, occupation?

2. Was the sampling frame a true or close representation of the target population?

3. Was some form of random selection used to select the sample, OR, was a census undertaken?
- Yes (LOW RISK): The study's target population was a close representation of the national population.

- No (HIGH RISK): The study's target population was clearly NOT representative of the national population.

- Yes (LOW RISK): The sampling frame was a true or close representation of the target population.

- No (HIGH RISK): The sampling frame was NOT a true or close representation of the target population.

- Yes (LOW RISK): A census was undertaken, $\mathrm{OR}$, some form of random selection was used to select the sample (e.g. simple random sampling, stratified random sampling, cluster sampling, systematic sampling).

- No (HIGH RISK): A census was NOT undertaken, AND some form of random selection was NOT used to select the sample.
The target population refers to the group of people or entities to which the results of the study will be generalised. Examples:

- The study was a national health survey of people 15 years and over and the sample was drawn from a list that included all individuals in the population aged 15 years and over. The answer is: Yes (LOW RISK).

- The study was conducted in one province only, and it is not clear if this was representative of the national population. The answer is: No (HIGH RISK).

- The study was undertaken in one village only and it is clear this was not representative of the national population. The answer is: No (HIGH RISK).

The sampling frame is a list of the sampling units in the target population and the study sample is drawn from this list. Examples:

- The sampling frame was a list of almost every individual within the target population. The answer is: Yes (LOW RISK).

- The cluster sampling method was used and the sample of clusters/villages was drawn from a list of all villages in the target population. The answer is: Yes (LOW RISK).

- The sampling frame was a list of just one particular ethnic group within the overall target population, which comprised many groups. The answer is: No (HIGH RISK).

A census collects information from every unit in the sampling frame. In a survey, only part of the sampling frame is sampled. In these instances, random selection of the sample helps minimise study bias. Examples:

- The sample was selected using simple random sampling. The answer is: Yes (LOW RISK).

- The target population was the village and every person in the village was sampled. The answer is: Yes (LOW RISK).

- The nearest villages to the capital city were selected in order to save on the cost of fuel. The answer is: No (HIGH RISK). 


\begin{tabular}{ll}
\hline \multicolumn{1}{c}{ Risk of bias item } & Criteria for answers (circle one option) \\
\hline $\begin{array}{l}\text { 4. Was the likelihood of non- } \\
\text { response bias minimal? }\end{array}$ & Yes (LOW RISK): The response rate for the \\
& study was $>/=75 \%$, OR, an analysis was \\
performed that showed no significant differ & ence in relevant demographic characteristics \\
between responders and non-responders \\
- No (HIGH RISK): The response rate was \\
$<75 \%$, and if any analysis comparing re- \\
sponders and non-responders was done, it \\
showed a significant difference in relevant \\
demographic characteristics between \\
responders and non-responders.
\end{tabular}

\section{Internal validity}

\section{Were data collected directly}

from the subjects (as

opposed to a proxy)? nition used in the study?

7. Was the study instrument that measured the parameter of interest (e.g., prevalence of low back pain) shown to have reliability and validity (if necessary)?
- Yes (LOW RISK): All data were collected directly from the subjects.

- No (HIGH RISK): In some instances, data were collected from a proxy.

- Yes (LOW RISK): An acceptable case definition was used.

- No (HIGH RISK): An acceptable case definition was NOT used.
- Yes (LOW RISK): The study instrument had been shown to have reliability and validity (if this was necessary), e.g. test-retest, piloting, validation in a previous study, etc.

- No (HIGH RISK): The study instrument had NOT been shown to have reliability or validity (if this was necessary).

- The response rate was $68 \%$; however, the researchers did an analysis and found no significant difference between responders and non-responders in terms of age, sex, occupation and socioeconomic status. The answer is: Yes (LOW RISK).

- The response rate was $65 \%$ and the researchers did NOT carry out an analysis to compare relevant demographic characteristics between responders and non-responders. The answer is: No (HIGH RISK).

- The response rate was $69 \%$ and the researchers did an analysis and found a significant difference in age, sex and socioeconomic status between responders and non-responders. The answer is: No (HIGH RISK).

A proxy is a representative of the subject. Examples:

- All eligible subjects in the household were interviewed separately. The answer is: Yes (LOW RISK).

- A representative of the household was interviewed and questioned about the presence of low back pain in each household member. The answer is: No (HIGH RISK).

- For a study on low back pain, the following case definition was used: "Low back pain is defined as activity-limiting pain lasting more than one day in the area on the posterior aspect of the body from the bottom of the 12th rib to the lower gluteal folds." The answer is: Yes (LOW RISK).

- For a study on back pain, there was no description of the specific anatomical location "back" referred to. The answer is: No (HIGH RISK).

- For a study on osteoarthritis, the following case definition was used: "Symptomatic osteoarthritis of the hip or knee, radiologically confirmed as Kellgren-Lawrence grade 2-4". The answer is: LOW RISK.

- The authors used the COPCORD questionnaire, which had previously been validated. They also tested the inter-rater reliability of the questionnaire. The answer is: Yes (LOW RISK).

- The authors developed their own questionnaire and did not test this for validity or reliability. The answer is: No (HIGH RISK) 


\begin{tabular}{|c|c|c|}
\hline Risk of bias item & Criteria for answers (circle one option) & Additional notes and examples \\
\hline $\begin{array}{l}\text { 8. Was the same mode of data } \\
\text { collection used for all } \\
\text { subjects? }\end{array}$ & $\begin{array}{l}\text { - Yes (LOW RISK): The same mode of data } \\
\text { collection was used for all subjects. } \\
\text { - No (HIGH RISK): The same mode of data } \\
\text { collection was NOT used for all subjects. }\end{array}$ & $\begin{array}{l}\text { The mode of data collection is the method used for collecting } \\
\text { information from the subjects. The most common modes are } \\
\text { face-to-face interviews, telephone interviews and self- } \\
\text { administered questionnaires. Examples: } \\
\text { - All eligible subjects had a face-to-face interview. The answer is: } \\
\text { Yes (LOW RISK). } \\
\text { - Some subjects were interviewed over the telephone and some } \\
\text { filled in postal questionnaires. The answer is: No (HIGH RISK). }\end{array}$ \\
\hline $\begin{array}{l}\text { 9. Was the length of the short- } \\
\text { est prevalence period for the } \\
\text { parameter of interest } \\
\text { appropriate? }\end{array}$ & $\begin{array}{l}\text { Yes (LOW RISK): The shortest prevalence } \\
\text { period for the parameter of interest was } \\
\text { appropriate (e.g. point prevalence, one-week } \\
\text { prevalence, one-year prevalence). } \\
\text { - No (HIGH RISK): The shortest prevalence } \\
\text { period for the parameter of interest was not } \\
\text { appropriate (e.g. lifetime prevalence) }\end{array}$ & $\begin{array}{l}\text { The prevalence period is the period that the subject is asked about } \\
\text { e.g. "Have you experienced low back pain over the previous } \\
\text { year?" In this example, the prevalence period is one year. The } \\
\text { longer the prevalence period, the greater the likelihood of the } \\
\text { subject forgetting if they experienced the symptom of interest } \\
\text { (e.g. low back pain). Examples: } \\
\text { - Subjects were asked about pain over the past week. The } \\
\text { answer is: Yes (LOW RISK). } \\
\text { - Subjects were only asked about pain over the past three years. } \\
\text { The answer is: No (HIGH RISK). }\end{array}$ \\
\hline $\begin{array}{l}\text { 10. Were the numerator(s) and } \\
\text { denominator(s) for the } \\
\text { parameter of interest } \\
\text { appropriate? }\end{array}$ & $\begin{array}{l}\text { Yes (LOW RISK): The paper presented } \\
\text { appropriate numerator(s) AND denominator(s) } \\
\text { for the parameter of interest (e.g. the preva- } \\
\text { lence of low back pain). } \\
\text { - No (HIGH RISK): The paper did present nu- } \\
\text { merator(s) AND denominator(s) for the } \\
\text { parameter of interest but one or more of } \\
\text { these were inappropriate. }\end{array}$ & $\begin{array}{l}\text { There may be errors in the calculation and/or reporting of the } \\
\text { numerator and/or denominator. Examples: } \\
\text { - There were no errors in the reporting of the numerator(s) AND } \\
\text { denominator(s) for the prevalence of low back pain. The answer } \\
\text { is: Yes (LOW RISK). } \\
\text { - In reporting the overall prevalence of low back pain (in both men } \\
\text { and women), the authors accidentally used the population of } \\
\text { women as the denominator rather than the combined popula- } \\
\text { tion. The answer is: No (HIGH RISK). }\end{array}$ \\
\hline \multicolumn{3}{|c|}{$\begin{array}{l}\text { 11. Summary item on the overall risk of study bias } \\
\text { - LOW RISK OF BIAS: Further research is very unlikely to change our confidence in the estimate. } \\
\text { - MODERATE RISK OF BIAS: Further research is likely to have an important impact on our confidence in the estimate and may change the estimate. } \\
\text { - HIGH RISK OF BIAS: Further research is very likely to have an important impact on our confidence in the estimate and is likely to change the estimate. }\end{array}$} \\
\hline \multicolumn{3}{|c|}{$\begin{array}{l}\text { NOTE. This questionnaire is reprinted from Hoy et al. }{ }^{27} \text { Questions } 5 \text { and } 9 \text { were not used. } \\
\text { COPCORD, Community Oriented Program in the Rheumatic Diseases. }\end{array}$} \\
\hline \multicolumn{3}{|c|}{$\begin{array}{l}\text { Supplementary Table 4. Study Characteristics } \\
<\text { See Supplementary Table 2.xlsx }>\end{array}$} \\
\hline \multicolumn{3}{|c|}{$\begin{array}{l}\text { Supplementary Table 5. Quality Appraisal } \\
<\text { See Supplementary Table 3.xlsx }>\end{array}$} \\
\hline
\end{tabular}




\begin{tabular}{|c|c|c|c|c|c|c|c|c|c|c|c|c|}
\hline \multirow[b]{2}{*}{ Study } & \multirow[b]{2}{*}{ Region } & \multirow[b]{2}{*}{$\mathrm{N}$} & \multicolumn{10}{|c|}{ Age, $y$} \\
\hline & & & $40-44$ & $45-49$ & $50-54$ & $55-59$ & $60-64$ & $65-69$ & $70-74$ & $75-79$ & $80-84$ & $85+$ \\
\hline \multicolumn{13}{|l|}{ With denominator } \\
\hline Li et al, ${ }^{65} 2018$ & United States & 34,161 & $102 / 5102$ & $\rightarrow$ & $387 / 10470$ & $\rightarrow$ & $475 / 11314$ & $\rightarrow$ & $265 / 5890$ & $\rightarrow$ & $48 / 1385$ & $\rightarrow$ \\
\hline Schramm et al, ${ }^{88} 2016$ & Europe & 1694 & - & $11 / 460$ & $\rightarrow$ & $9 / 610$ & $\rightarrow$ & $21 / 532$ & $\rightarrow$ & - & - & - \\
\hline \multicolumn{13}{|l|}{ Other studies } \\
\hline Abdeljawad et al, ${ }^{28} 2015$ & United States & 1910 & - & - & $6.8 \%$ & $\rightarrow$ & $8.9 \%$ & $\rightarrow$ & $5.3 \%$ & $\rightarrow$ & $15.2 \%$ & $\rightarrow$ \\
\hline Buda et $a l,{ }^{39} 2012$ & Europe & 985 & OR:1 & $\rightarrow$ & OR:5.8 & $\rightarrow$ & OR:5.8 & $\rightarrow$ & OR:9.3 & $\rightarrow$ & - & - \\
\hline ljspeert et al, ${ }^{56} 2016$ & Europe & 3364 & $6.0 \%$ & $\rightarrow$ & $8.3 \%$ & $\rightarrow$ & $9.0 \%$ & $\rightarrow$ & $8.4 \%$ & $\rightarrow$ & - & - \\
\hline
\end{tabular}

NOTE. Arrows convey that no specific number was reported for a particular cell and that numbers printed to the left apply.

OR, odds ratio.

Supplementary Table 7.Adenoma Prevalence by Age Across Autopsy Studies

\begin{tabular}{|c|c|c|c|c|c|c|c|c|c|c|c|c|c|c|c|}
\hline \multirow[b]{2}{*}{ Study } & \multirow[b]{2}{*}{$\mathrm{N}$} & \multicolumn{14}{|c|}{ Age, $y$} \\
\hline & & $20-24$ & $25-29$ & $30-34$ & $35-39$ & $40-44$ & $45-49$ & $50-54$ & $55-59$ & $60-64$ & $65-69$ & $70-74$ & $75-79$ & $80-84$ & $85+$ \\
\hline Arminski, $1961^{16, a}$ & 1000 & $2 / 14$ & $\rightarrow$ & $9 / 39$ & $\rightarrow$ & $23 / 123$ & $\rightarrow$ & $66 / 245$ & $\rightarrow$ & $107 / 309$ & $\rightarrow$ & $88 / 189$ & $\rightarrow$ & $36 / 81$ & $\rightarrow$ \\
\hline Blatt, ${ }^{17} 1961$ & 448 & - & - & $0 / 13$ & $\rightarrow$ & $4 / 23$ & $\rightarrow$ & $18 / 53$ & $\rightarrow$ & $38 / 106$ & $\rightarrow$ & $71 / 158$ & $\rightarrow$ & $41 / 95$ & $\rightarrow$ \\
\hline Bombi, ${ }^{18} 1988$ & 212 & $5 / 42$ & $\rightarrow$ & $\rightarrow$ & $\rightarrow$ & $\rightarrow$ & $\rightarrow$ & $7 / 28$ & $\rightarrow$ & $10 / 36$ & $\rightarrow$ & $15 / 59$ & $\rightarrow$ & $9 / 47$ & $\rightarrow$ \\
\hline Chapman, ${ }^{19} 1963$ & 443 & $0 / 2$ & $\rightarrow$ & $1 / 5$ & $\rightarrow$ & $4 / 20$ & $\rightarrow$ & $20 / 64$ & $\rightarrow$ & $72 / 118$ & $\rightarrow$ & $73 / 137$ & $\rightarrow$ & $56 / 95$ & $\rightarrow$ \\
\hline Clark et $\mathrm{al}^{20}{ }_{1985}$ & 680 & - & - & - & - & - & 17/152 & $\rightarrow$ & $27 / 147$ & $\rightarrow$ & $54 / 184$ & $\rightarrow$ & 76/197 & $\rightarrow$ & $\rightarrow$ \\
\hline Eide and Stalsberg, ${ }^{21} 1978$ & 280 & - & - & - & - & - & $15 / 52$ & $\rightarrow$ & $12 / 49$ & $\rightarrow$ & $31 / 83$ & $\rightarrow$ & $46 / 96$ & $\rightarrow$ & $\rightarrow$ \\
\hline Jass et $a_{1},{ }^{22} 1992$ & 297 & $0 / 42$ & $\rightarrow$ & $2 / 29$ & $\rightarrow$ & $3 / 27$ & $\rightarrow$ & $14 / 42$ & $\rightarrow$ & $15 / 50$ & $\rightarrow$ & $21 / 60$ & $\rightarrow$ & $17 / 47$ & $\rightarrow$ \\
\hline Rickert et al, ${ }^{23} 1979$ & 518 & - & - & - & - & $11 / 65$ & $\rightarrow$ & $19 / 59$ & $25 / 67$ & $31 / 64$ & $48 / 76$ & $42 / 69$ & $28 / 55$ & $39 / 63$ & $\rightarrow$ \\
\hline Stemmerman and Yatani, ${ }^{24} 1973$ & 202 & - & - & - & - & $6 / 14$ & $\rightarrow$ & $1 / 25$ & $\rightarrow$ & $32 / 54$ & $\rightarrow$ & $34 / 55$ & $\rightarrow$ & $35 / 54$ & $\rightarrow$ \\
\hline Vatn and Stalsberg, ${ }^{25} 1982$ & 445 & - & - & - & - & $3 / 45$ & $\rightarrow$ & $23 / 100$ & $\rightarrow$ & $31 / 100$ & $\rightarrow$ & $44 / 100$ & $\rightarrow$ & $47 / 100$ & $\rightarrow$ \\
\hline Williams et al, ${ }^{26} 1982$ & 365 & - & - & - & - & - & $15 / 82$ & $\rightarrow$ & $20 / 69$ & $\rightarrow$ & $43 / 108$ & $\rightarrow$ & $43 / 106$ & $\rightarrow$ & $\rightarrow$ \\
\hline
\end{tabular}

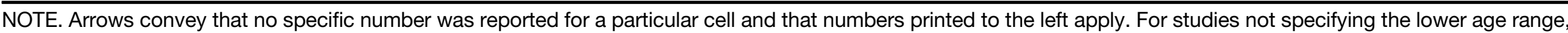
this was assumed to have a similar width as the other age ranges.

$R R$, relative risk.

${ }^{a}$ Rectal adenoma were not included in Arminski, 1961, suggesting true prevalence of adenomas in the colon and rectum may be higher. 
Supplementary Table 8. Adenoma Prevalence by Sex Across Autopsy Studies

\begin{tabular}{|c|c|c|c|c|}
\hline Study & $\begin{array}{c}\text { Male } \\
\text { patients, n }\end{array}$ & $\begin{array}{c}\text { Male patients } \\
\text { with } 1+\text { polyps, } n\end{array}$ & $\begin{array}{c}\text { Female } \\
\text { patients, } \mathrm{n}\end{array}$ & $\begin{array}{l}\text { Female patients } \\
\text { with } 1+\text { polyps, } n\end{array}$ \\
\hline Arminski, $1961^{16}$ & 575 & 198 & 425 & 134 \\
\hline Blatt, $^{17} 1961$ & 248 & 99 & 198 & 73 \\
\hline Clark et $\mathrm{al}^{20} 1985$ & 370 & 103 & 310 & 71 \\
\hline Eide and Stalsberg, ${ }^{21} 1978$ & 171 & 68 & 109 & 36 \\
\hline Jass et $a l,{ }^{22} 1992$ & 185 & 47 & 118 & 25 \\
\hline Rickert et al, ${ }^{23} 1979$ & 307 & 162 & 211 & 81 \\
\hline Stemmermann and Yatani, ${ }^{24} 1973$ & 125 & 80 & 77 & 45 \\
\hline Williams et $\mathrm{al}^{26} 1982$ & 198 & 73 & 167 & 48 \\
\hline
\end{tabular}

Supplementary Table 9.Adenoma Multiplicity Distribution Across Autopsy Studies

\begin{tabular}{lcccc}
\hline \multicolumn{1}{c}{ Study } & Patients, $\mathrm{n}$ & Patients with 1 polyp, $\mathrm{n}$ & Patients with 2 polyps, $\mathrm{n}$ & Patients with 3+ polyps, $\mathrm{n}$ \\
\hline Blatt, $^{17}{ }^{1961}$ & 173 & 72 & 41 & 60 \\
Stemmerman and Yatani, ${ }^{24}{ }_{1973}$ & 125 & 50 & 26 & 49 \\
Eide and Stalsberg, ${ }^{21}{ }^{1978}$ & 104 & 52 & 23 & 29 \\
\end{tabular}

Supplementary Table 10. Adenoma Size Distribution Across Autopsy Studies

\begin{tabular}{|c|c|c|c|c|}
\hline Study & Total polyps, $n$ & $\begin{array}{l}\text { Small polyps } \\
(0-5 \mathrm{~mm}), \mathrm{n}\end{array}$ & $\begin{array}{l}\text { Medium polyps, } \\
\quad(6-9 \mathrm{~mm}), \mathrm{n}\end{array}$ & $\begin{array}{l}\text { Large polyps, } \\
(10+\mathrm{mm}), \mathrm{n}\end{array}$ \\
\hline Arminski, $1961^{16}$ & 647 & 379 & 169 & 99 \\
\hline Blatt, ${ }^{17} 1961$ & 465 & 232 & 158 & 75 \\
\hline Bombi, ${ }^{18} 1988$ & 89 & 41 & 42 & 6 \\
\hline Eide and Stalsberg, ${ }^{21} 1978$ & 280 & 123 & 133 & 24 \\
\hline Jass et al, ${ }^{22} 1992$ & 149 & 58 & 64 & 27 \\
\hline Rickert et al, ${ }^{23} 1979$ & 629 & 275 & 257 & 97 \\
\hline Williams et al, ${ }^{26} 1982$ & 242 & 103 & 108 & 31 \\
\hline
\end{tabular}

Supplementary Table 11. Adenoma Location Distribution Across Autopsy Studies

\begin{tabular}{|c|c|c|c|c|}
\hline Arminski, $1961^{16}$ & 797 & 368 & 279 & 150 \\
\hline Blatt, ${ }^{17} 1961$ & 465 & 285 & 145 & 35 \\
\hline Chapman, ${ }^{19} 1963$ & 552 & 349 & 188 & 15 \\
\hline Clarke, ${ }^{20} 1985$ & 680 & 380 & 245 & 54 \\
\hline Eide and Stalsberg, ${ }^{21} 1978$ & 280 & 153 & 102 & 25 \\
\hline Williams et al, ${ }^{26} 1982$ & 242 & 139 & 71 & 32 \\
\hline
\end{tabular}


Supplementary Table 12. Characteristics of Studies Reporting Dysplasia in SSPs

\begin{tabular}{|c|c|c|c|c|c|c|c|c|}
\hline Study & Region & Colonoscopy indication & $\begin{array}{c}\text { Screen } \\
\text { examinations, \% }\end{array}$ & $\begin{array}{c}\text { Other } \\
\text { examinations, } \%\end{array}$ & Polyps or patients ${ }^{a}$ & $\mathrm{~N}$ & Dysplasia, \% & Large, \% \\
\hline Abdeljawad et al, ${ }^{28} 2015$ & North America & Screening & 100 & 0 & Patients & 225 & 5.8 & 22.7 \\
\hline Bouwens et $\mathrm{al}^{37} 2014$ & Europe & $\begin{array}{l}\text { Screening, symptoms, } \\
\text { or surveillance }\end{array}$ & $0-6.9$ & $93.1-100$ & Polyps & 140 & 42.9 & - \\
\hline Hazewinkel et al,,$^{52} 2014$ & Europe & Screening (trial) & 100 & 0 & Polyps & 111 & 26.1 & $23.5^{\mathrm{b}}$ \\
\hline ljspeert et al, ${ }^{56} 2016$ & Europe & Any except screening & 0 & 100 & Polyps & 399 & 3.8 & 21.4 \\
\hline ljspeert et al, ${ }^{57} 2017$ & Europe & Screening, or $\mathrm{FT}^{+}$patients & 34 & 66 & Patients & 1049 & 11.0 & 30.0 \\
\hline Lash et al, ${ }^{98} 2010$ & North America & Any & Unknown & Unknown & Patients & 2139 & 15.1 & - \\
\hline Pai et al, ${ }^{99} 2010$ & North America & Screening & 100 & 0 & Polyps & 68 & 7.4 & - \\
\hline Turner et al, ${ }^{92} 2018$ & North America & Any & Unknown & Unknown & Polyps & 25,848 & 3.7 & 33.6 \\
\hline
\end{tabular}

$\mathrm{FT}^{+}$, positive fecal test result.

${ }^{a}$ Proportion of polyps or patients.

${ }^{b}$ Proportion of patients with SSPs who have large SSPs.

Supplementary Table 13.Age at Detection of SSPs Across Studies

\begin{tabular}{|c|c|c|c|c|c|}
\hline Study & Region & Patients, N & $\begin{array}{l}\text { Age at Diagnosis of } \\
\text { SSPs With no Dysplasia, } y\end{array}$ & $\begin{array}{l}\text { Age at Diagnosis of SSPs } \\
\text { With Any Dysplasia, } y\end{array}$ & $\begin{array}{c}\text { Age at Diagnosis of } \\
\text { SSPs With High-Grade Dysplasia, } y\end{array}$ \\
\hline Bouwens et al, ${ }^{37} 2014$ & Europe & 140 & 61 & 66 & - \\
\hline Lash et al, ${ }^{98} 2010$ & United States & 2139 & 61 & 66 & 72 \\
\hline Pai et al, ${ }^{99} 2010$ & United States & 68 & 62.6 & 60.7 & \\
\hline Yang et al, ${ }^{101} 2015^{a}$ & United States & 11,201 & 60.8 & 65.6 & 69.9 \\
\hline Average $^{b}$ & & 13,548 & 60.8 & 65.6 & 70.2 \\
\hline
\end{tabular}

${ }^{a}$ Not included in Figure 7 of the article, the meta-analysis of prevalence of cytologic dysplasia in SSPs, because of overlap with Turner et al. ${ }^{92}$

${ }^{b}$ Average across studies weighted by study size. 